\title{
Front Matter: Volume 6519
}

, "Front Matter: Volume 6519," Proc. SPIE 6519, Advances in Resist Materials and Processing Technology XXIV, 651901 (26 April 2007); doi:

10.1117/12.732159

SPIE. Event: SPIE Advanced Lithography, 2007, San Jose, California, United States 


\title{
PROCEEDINGS OF SPIE
}

\section{Advances in Resist Materials and Processing Technology XXIV}

\author{
Qinghuang Lin \\ Editor
}

26-28 February 2007

San Jose, California, USA

Sponsored and Published by

SPIE-The International Society for Optical Engineering

Cooperating Organization

SEMATECH

Volume 6519

Part One of Two Parts

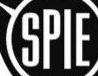

The International Society for Optical Engineering

Proceedings of SPIE-The International Society for Optical Engineering, 9780819466389, v. 6519

SPIE is an international technical society dedicated to advancing engineering and scientific applications of optical, photonic, imaging, electronic, and optoelectronic technologies. 
The papers included in this volume were part of the technical conference cited on the cover and title page. Papers were selected and subject to review by the editors and conference program committee. Some conference presentations may not be available for publication. The papers published in these proceedings reflect the work and thoughts of the authors and are published herein as submitted. The publisher is not responsible for the validity of the information or for any outcomes resulting from reliance thereon.

Please use the following format to cite material from this book:

Author(s), "Title of Paper," in Advances in Resist Materials and Processing Technology XXIV, edited by Qinghuang Lin, Proceedings of SPIE Vol. 6519 (SPIE, Bellingham, WA, 2007) Article CID Number.

ISSN 0277-786X

ISBN 9780819466389

Published by

SPIE-The International Society for Optical Engineering

P.O. Box 10, Bellingham, Washington 98227-0010 USA

Telephone 1 360/676-3290 (Pacific Time) · Fax 1 360/647-1445

http://www.spie.org

Copyright (C) 2007, The Society of Photo-Optical Instrumentation Engineers

Copying of material in this book for internal or personal use, or for the internal or personal use of specific clients, beyond the fair use provisions granted by the U.S. Copyright Law is authorized by SPIE subject to payment of copying fees. The Transactional Reporting Service base fee for this volume is $\$ 18.00$ per article (or portion thereof), which should be paid directly to the Copyright Clearance Center (CCC), 222 Rosewood Drive, Danvers, MA 01923. Payment may also be made electronically through CCC Online at http://www.copyright.com. Other copying for republication, resale, advertising or promotion, or any form of systematic or multiple reproduction of any material in this book is prohibited except with permission in writing from the publisher. The CCC fee code is 0277-786X/07/ \$18.00.

Printed in the United States of America. 


\section{Contents}

\section{Part One}

xvii Symposium Committees

xix Conference Committee

xxi Introduction

xxiii Plenary Paper: Lithography beyond 32nm: a role for imprint? M. Melliar-Smith, Molecular Imprints (USA)

xxxvii C. Grant Willson 2006 Best Award Paper: The effect of photoresist/topcoat properties on defect formation in immersion lithography

\section{SESSION 1 INVITED SESSION}

651902 Identifying materials limits of chemically amplified photoresists (Invited Paper) [6519-01] W. Wu, V. M. Prabhu, E. K. Lin, National Institute of Standards and Technology (USA)

651903 Emerging patterning materials: trends, challenges, and opportunities in patterning and materials by design (Invited Paper) [6519-02]

D. J. C. Herr, Semiconductor Research Corp. (USA)

\section{SESSION 2 MATERIALS AND PROCESSES FOR IMMERSION LITHOGRAPHY I}

651904 Fluoro-alcohol materials with tailored interfacial properties for immersion lithography [6519-03]

D. P. Sanders, L. K. Sundberg, R. Sooriyakumaran, P. J. Brock, R. A. DiPietro, H. D. Truong, D. C. Miller, IBM Almaden Research Ctr. (USA); M. C. Lawson, IBM Semiconductor Research and Development Ctr. (USA); R. D. Allen, IBM Almaden Research Ctr. (USA)

651905 Development of non-topcoat resist polymers for 193-nm immersion lithography [6519-04] N. Shirota, Y. Takebe, S.-Z. Wang, T. Sasaki, O. Yokokoji, Asahi Glass Co., Ltd. (Japan)

Pagination: Proceedings of SPIE follow an e-First publication model, with papers published first online and then in print and on CD-ROM. Papers are published as they are submitted and meet publication criteria. A unique, consistent, permanent citation identifier (CID) number is assigned to each article at the time of the first publication. Utilization of CIDs allows articles to be fully citable as soon they are published online, and connects the same identifier to all online, print, and electronic versions of the publication.

SPIE uses a six-digit CID article numbering system in which:

- The first four digits correspond to the SPIE volume number.

- The last two digits indicate publication order within the volume using a Base 36 numbering system employing both numerals and letters. The CID number appears on each page of the manuscript. The complete citation is used on the first page, and an abbreviated version on subsequent pages. 
651907 Building an immersion topcoat from the ground up: materials perspective [6519-06] M. Khojasteh, I. Popova, P. R. Varanasi, IBM Systems and Technology Group (USA); L. Sundberg, IBM Almaden Research Ctr. (USA); C. Robinson, D. Corliss, M. Lawson, IBM Systems and Technology Group. (USA); G. Dabbagh, M. Slezak, JSR Micro, Inc. (USA); M. Colburn, IBM Systems and Technology Group (USA); K. Petrillo, IBM Albany (USA)

651908 Novel materials design for immersion lithography [6519-07]

K. Wada, S. Kanna, H. Kanda, FUJIFILM Corp. (Japan)

SESSION 3 MATERIALS AND PROCESSES FOR IMMERSION LITHOGRAPHY II

651909 Novel high-index resists for 193-nm immersion lithography and beyond [6519-08]

I. Blakey, L. Chen, B. Dargaville, H. Liu, A. Whittaker, The Univ. of Queensland (Australia); W. Conley, Freescale Semiconductor, Inc. (USA); E. Piscani, G. Rich, A. Williams, P. Zimmerman, SEMATECH (USA)

65190A Screening of second-generation high-index liquids [6519-09] E. Hendrickx, S. Postnikov, P. Foubert, R. Gronheid, B. Kim, IMEC (Belgium)

65190B High-refractive index material design for ArF immersion lithography [6519-10] T. Furukawa, T. Kishida, T. Miyamatsu, K. Kawaguchi, K. Yamada, T. Tominaga, JSR Corp. (Japan); M. Slezak, JSR Micro, Inc. (USA); K. Hieda, JSR Corp. (Japan)

65190C Adapting immersion exposure to mass production by adopting a cluster of novel resistcoating/developing and immersion-exposure equipment [6519-11]

T. Fujiwara, J. Ishikawa, T. Kawakubo, Y. Ishii, Nikon Corp. (Japan); H. Kyoda, S. Wakamizu, T. Shimoaoki, Tokyo Electron Kyushu Ltd. (Japan)

65190D Immersion defectivity control by optimizing immersion materials and processes [6519-12] K. Nakano, H. Kato, S. Owa, Nikon Corp. (Japan)

65190E Measurement and evaluation of water uptake by resists, top coats, stacks, and correlation with watermark defects [6519-13]

P. Foubert, IMEC (Belgium); M. Kocsis, IMEC (Belgium) and Intel Corp. (USA); R. Gronheid, IMEC (Belgium); S. Kishimura, Matsushita Electric Industrial Co., LTD. (Japan); A. Soyano, IMEC (Belgium) and JSR Micro (Belgium); K. Nafus, IMEC (Belgium) and Tokyo Electron Kyushu Ltd. (Japan); N. Stepanenko, IMEC (Belgium) and Infineon Technologies (Germany); J. De Backer, N. Vandenbroeck, M. Ercken, IMEC (Belgium)

\section{SESSION 4 RESIST MATERIALS}

65190F High-performance 193-nm photoresists based on fluorosulfonamide [6519-14] W. Li, K.-J. Chen, R. Kwong, M. C. Lawson, M. Khojasteh, I. Popova, P. R. Varanasi, IBM Semiconductor Research and Development Ctr. (USA); T. Shimokawa, Y. Yamaguchi, S. Kusumoto, M. Sugiura, T. Kawakami, JSR Corp. (Japan); M. Slezak, G. Dabbagh, Z. Liu, JSR Micro, Inc. (USA) 
$651906 \quad$ Novel diamantane polymer platform for enhanced etch resistance [6519-15]

M. Padmanaban, S. Chakrapani, G. Lin, T. Kudo, D. Parthasarathy, D. Rahman,

C. Anyadiegwu, C. Antonio, R. R. Dammel, AZ Electronic Materials USA Corp. (USA); S. Liu,

F. Lam, A. Waitz, MolecularDiamond Technologies, Chevron Technology Ventures (USA);

M. Yamagchi, T. Maehara, Tokuyama Corp. (Japan)

65190H Hybrid optical: electron-beam resists [6519-16]

D. M. Lennon, S. J. Spector, T. H. Fedynyshyn, T. M. Lyszczarz, M. Rothschild, MIT Lincoln Lab.

(USA); J. Thackeray, K. Spear-Alfonso, Rohm and Haas Electronic Materials (USA)

65190I Evaluation of immersion lithography processes for 55-nm node logic devices [6519-73]

T. Nakata, T. Kodama, M. Komori, N. Onoda, T. Uchiyama, NEC Electronics Corp. (Japan)

65190J Photo-deprotection resist based on photolysis of o-nitrobenzyl phenol ether; challenge to half-pitch 22 nm using near-field lithography [6519-19]

T. Ito, A. Terao, Y. Inao, T. Yamaguchi, N. Mizutani, Canon Inc. (Japan)

65190K Enhancing photoresist performance with an adhesion promoting photo-acid generator [6519-20]

S. Sharma, Lawrence Berkeley National Lab. (USA); R. P. Meagley, Lawrence Berkeley National Lab. (USA) and Intel Corp. (USA)

$65190 \mathrm{~L}$ Second-generation radiation sensitive developable bottom anti-reflective coatings (DBARC) and implant resists approaches for 193-nm lithography [6519-21]

F. Houlihan, A. Dioses, M. Toukhy, A. Romano, J. Oberlander, H. Wu, S. Mullen, A. Krawicz, P. LU, M. Neisser, AZ Electronic Materials USA Corp. (USA)

65190M Spin-on trilayer approaches to high NA 193nm lithography [6519-22]

D. J. Abdallah, D. McKenzie, A. Timko, A. Dioses, F. Houlihan, D. Rahman, S. Miyazaki, R. Zhang, W. Kim, H. WU, L. Pylneva, P.-H. LU, M. Neisser, R. R. Dammel, AZ Electronic Materials USA Corp. (USA); J. J. Biafore, KLA Tencor (USA)

65190N Progress of hard mask material for multilayer stack application [6519-122] H. Harada, K. Yonemura, T. Tanaka, D. Kawana, N. Yamashita, K. Ohmori, Tokyo Ohka Kogyo Co., Ltd. (Japan)

651900 Silicon-based anti-reflective spin-on hardmask materials with improved storage stability for 193-nm lithography [6519-24]

S. K. Kim, S. H. Lim, D. Kim, S. R. Koh, M. Kim, H. C. Yoon, D. S. Uh, J. S. Kim, T. Chang,

Samsung Cheil Industries, Inc. (South Korea)

65190P Novel developers for positive tone EUV photoresists [6519-25]

G. Sharma, S. Sharma, M. Rattner, Lawrence Berkeley National Lab. (USA); R. P. Meagley, Lawrence Berkeley National Lab. (USA) and Intel Corp. (USA); M. Tanaka, T. Shimokawa, JSR Corp. (Japan); H. Sugita, T. Wang, A. Shiota, JSR Micro Inc. (USA) 
65190Q The application of high-refractive index photoresist for 32-nm device level imaging [6519-26]

W. Conley, Freescale Semiconductor, Inc. (USA)

65190R Performance of chemically amplified resists at half-pitch of $\mathbf{4 5} \mathbf{~ n m}$ and below [6519-27] Y. Wei, Qimonda North America Corp. (USA); M. Bender, Qimonda Dresden GmbH \& Co. OHG (Germany); W.-D. Domke, Qimonda AG (Germany); A. Laessig, Qimonda Dresden GmbH \& Co. OHG (Germany); M. Sebald, Qimonda AG (Germany); S. Trogisch, Qimonda Dresden GmbH \& Co. OHG (Germany); D. Back, Qimonda North America Corp. (USA)

65190S Evaluation of ArF lithography for 45-nm node implant layers [6519-28]

T. C. Bailey, IBM (USA); J. Maynollo, Infineon Technologies North America (USA); J. J. Perez, I. Popova, B. Zhang, IBM (USA)

65190T Characterization of photo-acid redeposition in 193-nm photoresists [6519-29]

T. Wallow, Advanced Micro Devices, Inc. (USA); M. Plat, Z. Zhang, B. MacDonald,

J. Bernard, J. Romero, Spansion LLC. (USA); B. La Fontaine, H. J. Levinson, Advanced Micro Devices, Inc. (USA)

$65190 \mathrm{U}$ A novel plasma-assisted shrink process to enlarge process windows of narrow trenches and contacts for 45-nm node applications and beyond [6519-30]

M. Op de Beeck, J. Versluijs, Z. Tőkei, S. Demuynck, J.-F. De Marneffe, W. Boullart, S. Vanhaelemeersch, IMEC (Belgium); H. Zhu, P. Cirigliano, E. Pavel, R. Sadjadi, J. Kim, Lam Research Corp. (USA)

\section{SESSION 7 RESIST PROCESSES AND SIMULATION}

65190V A novel method for characterizing resist performance [6519-31]

D. Van Steenwinckel, NXP Semiconductors (Belgium); R. Gronheid, IMEC (Belgium); J. H. Lammers, Philips Research Europe (Netherlands); A. M. Meyers, IMEC (Belgium) and Intel Corp. (USA); F. Van Roey, P. Willems, IMEC (Belgium)

65190W The tri-lateral challenge of resolution, photospeed, and LER: scaling below 50nm? [6519-32] R. L. Bristol, Intel Corp. (USA)

65190X PAG segregation during exposure affecting innate material roughness [6519-33]

T. H. Fedynyshyn, D. K. Astolfi, A. Cabral, MIT Lincoln Lab. (USA); J. Roberts, Intel Corp. (USA)

65190Y Mechanistic simulation of line-edge roughness [6519-34]

J. J. Biafore, M. D. Smith, S. A. Robertson, T. Graves, KLA-Tencor Corp. (USA)

651902 The characterization of photoresist for accurate simulation beyond Gaussian diffusion [6519-35]

L. Wang, P. Wu, Q. WU, H. Ding, X. Li, C. Sun, Shanghai Huahong NEC Electronics Co., Ltd. (China) 
651910 Direct measurement of the in-situ developed latent image: the residual swelling fraction [6519-37]

V. M. Prabhu, B. D. Vogt, S. Kang, A. Rao, E. K. Lin, S. K. Satija, National Institute of Standards and Technology (USA); K. Turnquest, SEMATECH (USA)

651911 Fundamental limits to EUV photoresist [6519-38]

G. M. Gallatin, Applied Math Solutions, LLC (USA); P. Naulleau, Lawrence Berkeley National Lab. (USA) and Univ. at Albany (USA); R. Brainard, Univ. at Albany (USA)

651912 Etch resistance: comparison and development of etch rate models [6519-39]

D. Perret, Rohm and Haas Electronic Materials (France); C. E. Andes, K.-S. Cheon, M. Sobhian, C. R. Szmanda, G. G. Barclay, P. Trefonas III, Rohm and Haas Electronic Materials LLC (USA)

651913 Dissolution behavior of resist polymers studied by Quartz-Crystal-Microbalance method II [6519-40]

M. Toriumi, Lab. for Interdisciplinary Science and Technology (Japan); F. Okabe,

M. Kitayama, Kuraray, Co., Ltd. (Japan)

651915 Component segregation in model chemically amplified resists [6519-43]

J. T. Woodward, National Institute of Standards and Technology (USA); T. H. Fedynyshyn,

D. K. Astolfi, S. Cann, MIT Lincoln Lab. (USA); J. M. Roberts, M. J. Leeson, Intel Corp. (USA)

651916 FTIR measurements of compositional heterogeneities [6519-44]

S. Kang, B. D. Vogt, W. Wu, V. M. Prabhu, D. L. VanderHart, A. Rao, E. K. Lin, National Institute of Standards and Technology (USA); K. Turnquest, SEMATECH (USA)

651917 Changes in resist glass transition temperatures due to exposure [6519-45]

T. H. Fedynyshyn, I. Pottebaum, A. Cabral, MIT Lincoln Lab. (USA); J. Roberts, Intel Corp. (USA)

651918 A study on the material design for the reduction of LWR [6519-46]

H. Tsubaki, T. Yamanaka, F. Nishiyama, K. Shitabatake, FUJIFILM Co., Ltd. (Japan)

651919 Line-edge roughness in 193-nm resists: lithographic aspects and etch transfer [6519-162] T. Wallow, A. Acheta, Y. Ma, Advanced Micro Devices, Inc. (USA); A. Pawloski, Affymetrix, Corp. (USA); S. Bell, B. Ward, Spansion LLC (USA); C. Tabery, B. La Fontaine, R. Kim,

S. McGowan, H. J. Levinson, Advanced Micro Devices, Inc. (USA)

65191A Impact of line-width roughness on Intel's 65-nm process devices [6519-48]

M. Chandhok, S. Datta, D. Lionberger, S. Vesecky, Intel Corp. (USA) 
65191C Impact of curing kinetics and materials properties on imprint characteristics of resists for UV nano-imprint lithography [6519-50]

F. A. Houle, A. Fornof, R. Sooriyakumaran, H. Truong, D. C. Miller, M. I. Sanchez, B. Davis, T. Magbitang, R. D. Allen, M. W. Hart, G. Dubois, IBM Almaden Research Ctr. (USA)

65191D Material design of negative-tone polyphenol resist for EUV and EB lithography [6519-51] K. Kojima, Hitachi, Ltd. (Japan); S. Mori, Hitachi ULSI Systems. Co., Ltd. (Japan); D. Shiono, H. Hada, J. Onodera, Tokyo Ohka Kogyo Co., Ltd. (Japan)

$65191 \mathrm{E}$ Photosensitivity and line-edge roughness of novel polymer-bound PAG photoresists [6519-52]

C.-T. Lee, Georgia Institute of Technology (USA); M. Wang, N. D. Jarnagin, K. E. Gonsalves, The Univ. of North Carolina, Charlotte (USA); J. M. Roberts, W. Yueh, Intel Corp. (USA); C. L. Henderson, Georgia Institute of Technology (USA)

$65191 \mathrm{~F} \quad$ Novel anionic photoacid generator (PAGs) and photoresist for sub-50-nm patterning by EUVL and EBL [6519-53]

M. Wang, Univ. of North Carolina, Charlotte (USA); C.-T. Lee, C. L. Henderson, Georgia Institute of Technology (USA); W. Yueh, J. M. Roberts, Intel Corp. (USA); K. E. Gonsalves, Univ. of North Carolina, Charlotte (USA)

\section{SESSION 11 NOVEL PROCESSES/APPLICATIONS}

$65191 \mathrm{H}$ Self-aligned, self-assembled organosilicate line patterns of $\sim 20 \mathrm{~nm}$ half-pitch from blockcopolymer mediated self assembly [6519-55]

H.-C. Kim, J. Cheng, C. Rettner, O.-H. Park, R. Miller, M. Hart, L. Sundström, IBM Almaden Research Ctr. (USA); Y. Zhang, IBM T.J. Watson Research Ctr. (USA)

651911 Gray-scale lithography of photosensitive polyimide and its graphitization [6519-56] S. Akbar, Virginia State Univ. (USA); E. Imhoff, F. Kub, Naval Research Lab. (USA)

$65191 \mathrm{~J}$ A novel top surface imaging approach utilizing direct-area selective atomic layer deposition of hardmasks [6519-57]

A. Sinha, D. W. Hess, C. L. Henderson, Georgia Institute of Technology (USA)

65191K Novel photodefinable low-k dielectric polymers based on polybenzoxazines [6519-58] M. Romeo, Georgia Institute of Technology (USA); K. Yamanaka, Georgia Institute of Technology (USA) and Central Glass Co., Ltd. (Japan); K. Maeda, Central Glass Co., Ltd. (Japan); C. L. Henderson, Georgia Institute of Technology (USA)

65191L Patterning of biomolecules on a biocompatible nonchemically amplified resist [6519-59] J.-B. Kim, R. Ganesan, S. Y. Yoo, Korea Advanced Institute of Science and Technology (South Korea); J.-H. Choi, Advanced Radiation Technology Institute, Korea Atomic Energy Research Institute (South Korea); S. Y. Lee, Korea Advanced Institute of Science and Technology (South Korea) 
65191M Resist evaluation for EUV application at ASET [6519-60]

D. Goo, Y. Tanaka, Y. Kikuchi, H. Oizumi, I. Nishiyama, Association of Super-Advanced

Electronic Technologies (Japan)

$65191 \mathrm{~N}$ Molecular glass photoresists containing photoacid generator functionality: a route to a single-molecule photoresist [6519-61]

R. A. Lawson, C.-T. Lee, R. Whetsell, Georgia Institute of Technology (USA); W. Yueh,

J. Roberts, Intel Corp. (USA); L. Tolbert, C. L. Henderson, Georgia Institute of Technology (USA)

651910 The resist materials study for the outgassing reduction and LWR improvement in EUV lithography [6519-62]

S. Masuda, S. Kamimura, S. Hirano, W. Hoshino, K. Mizutani, FUJIFILM Corp. (Japan)

65191P An analysis of EUV-resist outgassing measurements [6519-63]

K. R. Dean, SEMATECH (USA); I. Nishiyama, H. Oizumi, Association of Super-Advanced Electronics Technologies (Japan); A. Keen, BOC Edwards, Inc. (USA); H. Cao, W. Yueh, Intel Corp. (USA); T. Watanabe, Univ. of Hyogo (Japan); P. Lacovig, L. Rumiz, Sincrotrone Trieste S.c.p.A (Italy); G. Denbeaux, SUNY, Univ. at Albany (USA); J. Simon, CEA-LETI (France)

\section{Part Two}

\section{POSTER SESSION: MATERIALS AND PROCESSES FOR IMMERSION LITHOGRAPHY}

$65191 \mathrm{Q}$ Contact angles and structure/surface property relationships of immersion materials [6519-64]

L. K. Sundberg, D. P. Sanders, R. Sooriyakumaran, P. J. Brock, R. D. Allen, IBM Almaden

Research Ctr. (USA)

651915 Mechanism of immersion specific defects with high receding-angle topcoat [6519-67]

M. Terai, T. Kumada, Mitsubishi Electric Corp. (Japan); T. Ishibashi, T. Hagiwara, T. Hanawa, Renesas Technology Corp. (Japan); T. Ando, Tokyo Ohka Kogyo Co., Ltd. (Japan);

T. Matsunobe, K. Okada, Y. Muraji, K. Yoshikawa, N. Man, Toray Research Ctr. Inc. (Japan)

$65191 \mathrm{D}$ Defectivity reduction studies for ArF immersion lithography [6519-68]

K. Matsunaga, T. Kondoh, H. Kato, Y. Kobayashi, K. Hayasaki, S. Ito, Toshiba Corp. (Japan);

A. Yoshida, SanDisk Corp. (Japan); S. Shimura, T. Kawasaki, H. Kyoda, Tokyo Electron Kyushu Ltd. (Japan)

$65191 \mathrm{~V}$ Study on the reduction of defects in immersion lithography [6519-70]

K. Ban, S. Park, C. Bok, H. Lim, J. Heo, H. Chun, J. Kang, S. Moon, Hynix Semiconductor Inc. (South Korea)

65191W Modified polymer architecture for immersion lithography [6519-71]

S. S. Kim, J. W. Kim, J. Y. Lee, S. K. Oh, S. H. Lee, J. W. Kim, J. W. Lee, D. B. Kim, J. Kim, Dongjin Semichem Co. Ltd. (South Korea); K. D. Ban, C. K. Bok, S.-C. Moon, Hynix Semiconductor Inc. (South Korea) 
$65191 \mathrm{X}$ Tailoring surface properties of ArF resists thin films with functionally graded materials (FGM) [6519-72]

I. Takemoto, N. Ando, K. Edamatsu, Y. Fuji, K. Kuwana, K. Hashimoto, J. Funase,

H. Yokoyama, Sumitomo Chemical Co., Ltd. (Japan)

$65191 Y$ Development of top coat materials for ArF immersion lithography [6519-17]

Y. Takebe, N. Shirota, T. Sasaki, O. Yokokoji, Asahi Glass Co., Ltd. (Japan)

651912 Transfer mechanism of defects on topcoat to resist pattern in immersion lithography process and effects on etching process [6519-77]

N. Takahashi, S. Shimura, T. Kawasaki, Tokyo Electron Kyushu, Ltd. (Japan)

651920 Models for predicting the index of refraction of compounds at 193 and $589 \mathrm{~nm}$ [6519-78]

R. L. Brainard, S. Kruger, E. Block, Univ. at Albany, SUNY (USA)

651921 Outlook for potential third-generation immersion fluids [6519-80]

J. López-Gejo, J. T. Kunjappu, Columbia Univ. (USA); J. Zhou, B. W. Smith, Rochester Institute of Technology (USA); P. Zimmerman, SEMATECH (USA); W. Conley, Freescale

Semiconductor, Inc. (France); N. J. Turro, Columbia Univ. (USA)

651922 Behavior and effects of water penetration in 193-nm immersion lithography process materials [6519-82]

T. Niwa, Tokyo Electron Kyushu Ltd. (Japan); S. Scheer, M. Carcasi, Tokyo Electron America, Inc. (USA); M. Enomoto, T. Tomita, K. Hontake, H. Kyoda, J. Kitano, Tokyo Electron Kyushu Ltd. (Japan)

651923 Process optimization for developer soluble immersion topcoat material [6519-83] H. Nakagawa, K. Goto, M. Shima, J. Takahashi, T. Shimokawa, JSR Corp. (Japan); K. Ichino, N. Nagatani, H. Kyoda, K. Yoshihara, Tokyo Electron Kyushu Ltd. (Japan)

651924 Defect transfer from immersion exposure process to post processing and defect reduction using novel immersion track system [6519-84]

O. Miyahara, T. Shimoaoki, S. Wakamizu, J. Kitano, Tokyo Electron Kyushu Ltd. (Japan);

Y. Ono, S. Maejima, T. Hanawa, K. Suko, Renesas Technology Corp. (Japan)

651925 Polymer structure modifications for immersion leaching control [6519-85]

S. H. Lee, J. W. Kim, J. W. Kim, S. K. Oh, C. S. Park, J. Y. Lee, S. S. Kim, J. W. Lee, D. Kim, J. Kim, Dongjin Semichem Co. Ltd. (South Korea); K. D. Ban, C. K. Bok, S. C. Moon, Hynix

Semiconductor Co., Ltd. (South Korea)

651926 A multi-tiered approach to $193 \mathrm{~nm}$ immersion defect reduction through track process adjustments [6519-86]

E. Ng, Spansion Inc. (USA); J. Hooge, Tokyo Electron America Inc. (USA)

651927 Formulated surface conditioners in 50-nm immersion lithography: simultaneously reducing pattern collapse and line-width roughness [6519-87]

M. Sugiyama, M. Sanada, Sokudo, Co., Ltd. (Japan); S. Wang, P. Wong, S. Sinkwitz, ASML Netherlands B.V. (Netherlands); M. Jaramillo, Jr., G. Parris, Air Products and Chemicals, Inc. (USA) 
651928 BARC (bottom anti-reflective coating) for immersion process [6519-89]

Y. Hiroi, T. Kishioka, R. Sakamoto, D. Maruyama, T. Ohashi, T. Ishida, S. Kimura, Y. Sakaida,

H. Watanabe, Nissan Chemical Industries, Ltd. (Japan)

651929 Organic ArF bottom anti-reflective coatings for immersion lithography [6519-90]

Z. Xiang, H. Zhuang, H. WU, J. Shan, D. Abdallah, J. Yin, S. Mullen, H. Yao, E. Gonzalez, M. Neisser, AZ Electronic Materials USA Corp. (USA)

65192A Multilayer BARCs for hyper-NA immersion lithography process [6519-91]

Y. Sakaida, S. Takei, M. Nakajima, S. Kimura, T. Sakaguchi, K. Hashimoto, H. Imamura, Nissan Chemical Industries, Ltd. (Japan)

65192B Initial process evaluation for next generation immersion technology node [6519-92]

T. Tomita, K. Nafus, S. Hatakeyama, H. Kosugi, M. Enomoto, Tokyo Electron Kyushu Ltd. (Japan); S. Inoue, K. Ruck, H. Weichert, Tokyo Electron Europe Ltd. (Germany);

M. B. Mantecon, R. Stegen, C. de Groot, R. Moerman, ASML Netherlands B.V. (Netherlands)

POSTER SESSION: RESIST MATERIALS

65192C Novel polymeric anionic photo-acid generators (PAGs) and photoresists for sub-100-nm patterning by 193-nm lithography [6519-93]

M. Wang, N. D. Jarnagin, Univ. of North Carolina, Charlotte (USA); W. Yueh, J. M. Roberts, Intel Corp. (USA); M. Tapia-Tapia, N. Batina, Univ. Autonoma Metropolitana, Iztapalapa (Mexico); K. E. Gonsalves, Univ. of North Carolina, Charlotte (USA)

65192E Development of nanocomposite resists with high plasma etch resistance [6519-96] C. Chen, H. Zhuang, P.-H. LU, M. Neisser, G. Pawlowski, AZ Electronic Materials USA Corp. (USA)

65192F Chemical composition distribution analysis of photoresist copolymers and influence on ArF lithographic performance [6519-97]

H. Momose, A. Yasuda, A. Ueda, T. Iseki, Mitsubishi Rayon Co., Ltd. (Japan); K. Ute, Tokushima Univ. (Japan); T. Nishimura, R. Nakagawa, T. Kitayama, Osaka Univ. (Japan)

$65192 \mathrm{G}$ Single component chemically-amplified resist based on dehalogenation of polymer [6519-98]

H. Yamamoto, T. Kozawa, S. Tagawa, Osaka Univ. (Japan); K. Ohmori, M. Sato, H. Komano, Tokyo Ohka Kogyo Co., Ltd. (Japan)

$65192 \mathrm{H} \quad$ Novel 193-nm positive photoresist composed of ester acetal polymer without phenyl group [6519-99]

L. Wang, X. Zhai, Y. Huo, Beijing Normal Univ. (China)

651921 Two-component photoresists based on acidolytic cleavage of novel ester acetal polymer [6519-100]

L. Wang, Z. Chu, L. Cheng, Beijing Normal Univ. (China)

65192J Nonchemically amplified resists for deep-UV lithography [6519-101]

R. Ganesan, S. Kim, S. K. Youn, Y. Cho, J.-M Yun, J.-B. Kim, Korea Advanced Institute of Science and Technology (South Korea) 
65192L Non-ionic photoacid generators for chemically amplified resists: evaluation results on the application-relevant properties [6519-103]

T. Asakura, H. Yamato, Y. Nishimae, M. Ohwa, Ciba Specialty Chemicals K.K. (Japan)

65192M PAG distribution and acid thermal diffusion study in ultra-thick chemically amplified resist films [6519-104]

M. Toukhy, M. Paunescu, C. Chen, G. Pawlowski, AZ Electronic Materials USA Corp. (USA)

65192N Study of 193nm resist degradation under various etch chemistries [6519-105]

A. Bazin, STMicroelectronics (France) and Lab. d'Electronique de Technologie de I'Information, CNRS (France); M. May, STMicroelectronics (France); E. Pargon, Lab. d'Electronique de Technologie de l'Information, CNRS (France); B. Mortini, STMicroelectronics (France); O. Joubert, Lab. d'Electronique de Technologie de I'Information, CNRS (France)

651920 Development of high-performance multi-layer resist process with hardening treatment [6519-106]

Y. Ono, T. Ishibashi, A. Yamaguchi, T. Hanawa, M. Tadokoro, K. Yoshikawa, K. Yonekura, Renesas Technology Corp. (Japan); K. Matsuda, T. Matsunobe, Toray Research Ctr. Inc. (Japan); Y. Fujii, T. Tanaka, Tokyo Ohka Kogyo Co., Ltd. (Japan)

$65192 \mathrm{P}$ Correlation between etching and optical properties of organic films for multilayer resist [6519-107]

E. Soda, F. Koba, S. Kondo, S. Ogawa, S. Saito, Semiconductor Leading Edge Technologies, Inc. (Japan)

65192Q Rework/stripping of multilayer materials for FEOL and BEOL integration using single wafer tool techniques [6519-108]

S. Turner, Brewer Science, Inc. (USA)

65192R Spin-on Organic Hardmask Materials in 70nm Devices [6519-109]

C. Oh, D. Uh, D. Kim, J. Lee, H. Yun, I. Nam, M. Kim, K. Yoon, K. Hyung, N. Tokareva,

H. Cheon, J. Kim, T. Chang, Cheil Industries, Inc. (South Korea)

65192S Materials for and performance of multilayer lithography schemes [6519-110] M. Weimer, Y. Wang, C. J. Neef, J. Claypool, K. Edwards, Z. Zu, Brewer Science, Inc. (USA)

65192T Advanced developer-soluble gap-fill materials and applications [6519-111] R. Huang, D. Sullivan, A. Qin, S. Brown, Brewer Science, Inc. (USA)

$65192 \mathrm{U}$ Novel low-reflective index fluoropolymers-based top anti-reflective coatings (TARC) for 193-nm lithography [6519-112]

T. Yamashita, T. Hayami, T. Ishikawa, T. Kanemura, H. Aoyama, Daikin Industries, Ltd. (Japan)

$65192 \mathrm{~V}$ Effect of solvents and cross-link reaction group concentration on via filling performance in gap fill materials [6519-113]

S. Takei, Y. Sakaida, T. Shinjo, Nissan Chemical Industries, Ltd. (Japan) 
65192W Optimization of hardmask for dual anti-reflection layers [6519-114]

J.-H. Kim, J. Kim, K. Kim, Dongbu Electronics Co., Ltd. (South Korea)

65192X A novel approach to developer-soluble anti-reflective coatings for 248-nm lithography [6519-115]

R.-M. L. Mercado, J. A. Lowes, C. A. Washburn, D. J. Guerrero, Brewer Science, Inc. (USA)

$65192 \mathrm{Y}$ Optimization of material and process parameter for minimizing defect in implementation of MFHM process [6519-116]

K. Lee, J. Heo, K. Ban, H. Seo, G. Lee, W. Kim, J. Cho, J. Sun, S. Lee, C. Bok, S. Moon, J. Kim, Hynix Semiconductor Inc. (South Korea)

65192Z A novel 248-nm wet-developable BARC for trench applications [6519-118]

C. J. Neef, D. Thomas, Brewer Science, Inc. (USA)

651930 Wet-recess gap-fill materials for an advanced dual damascene process [6519-119]

T. Shinjo, S. Takei, Y. Horiguchi, Y. Nakajima, Nissan Chemical Industries, Ltd. (Japan)

651933 Novel approach of UV cross- link process for advanced planarization technology in 32-45 nm lithography [6519-124]

S. Takei, Y. Horiguchi, T. Shinjo, H. Bang-Ching, Y. Mano, Y. Nakajima, Nissan Chemical Industries, Ltd. (Japan); M. Muramatsu, M. Iwashita, K. Tsuchiya, Tokyo Electron Ltd. (Japan)

651934 Overcome the challenge of CD-bias with organic bottom anti-reflective coating removal process [6519-125]

S. Yanovich, G. Krasnikov, O. Gushchin, JSC Mikron (Russia)

651935 Thin bilayer resists for 193-nm and future photolithography II [6519-126]

Y. Hishiro, M. Hyatt, Micron Technology, Inc. (USA)

651936 Radiation sensitive developable bottom anti-reflective coating (DBARC) for 193nm lithography: first generation [6519-127]

M. Toukhy, J. Oberlander, S. Mullen, P. LU, M. Neisser, AZ Electronic Materials USA Corp. (USA)

\section{POSTER SESSION: RESIST PROCESSING TECHNOLOGY}

651937 Post exposure bake unit equipped with wafer-shape compensation technology [6519-128] S. Goto, A. Morita, K. Oyama, S. Hori, K. Matsuchika, H. Taniguchi, Sokudo Co., Ltd. (Japan)

651939 Reducing bubbles and particles associated with photoresist packaging materials and dispense systems [6519-132]

W. B. Alexander, K. T. O'Dougherty, W. Liu, H. Yan, K. Mikkelsen, ATMl, Inc. (USA)

65193A Resist evaluation for contact hole patterning with thermal flow process [6519-133] R. Tiron, C. Petitdidier, C. Sourd, CEA, LETI (France); D. De Simone, G. Cotti, E. Annoni, STMicroelectronics (Italy); B. Mortini, STMicroelectronics (France)

65193C Effect of novel rinsing material and surfactant treatment on the resist pattern performance [6519-135]

V. Huang, C. C. Chiv, C. A. Lin, C. Y. Chang, T. S. Gau, B. J. Lin, Taiwan Semiconductor Manufacturing Co., Ltd. (Taiwan) 
65193D Impact of airborne NH3 and humidity against wafer-to-wafer CD variation in ArF lithography through 45-nm technology node [6519-136]

R. Naito, Y. Matsuda, M. Shioguchi, T. Shibata, Tokyo Electron Kyushu Ltd. (Japan)

65193E Proximity effect correction for the chemical shrink process of different type contact holes [6519-138]

W. H. Hsieh, H. J. Liu, W. B. Wu, C. L. Shin, J. P. Lin, Nanya Technology Corp. (Taiwan)

65193F Mechanism of post develop stain defect and resist surface condition [6519-140] M. Harumoto, A. Yamaguchi, A. Hisai, Sokudo Co., Ltd. (Japan)

65193G New ArF resist introduction for process through-put enhancement [6519-141] M.-S. Kim, H.-W. Ryu, H.-G. Lee, H.-J. Kim, K.-C. Shim, M.-G. Gil, H.-S. Kang, Hynix Semiconductor Inc. (South Korea)

65193H A heater plate assisted integrated bake/chill system for photoresist processing [6519-142] H-T. Chua, The Univ. of Western Australia (Australia); A. Tay, Y. Wang, X. Wu, National Univ. of Singapore (Singapore)

651931 Molecular contamination control technologies for high-volume production phase in highNA 193-nm lithography [6519-143]

T. Nakano, T. Tanahashi, A. Imai, K. Yamana, T. Shimotsu, Nichias Corp. (Japan);

N. Takahashi, Tokyo Electron AT Ltd. (Japan); M. Shioguchi, Y. Matsuda, J. Kitano, Tokyo

Electron Kyushu Ltd. (Japan)

65193J Printing of structures less than $0,3 \mu \mathrm{m}$ by $\mathrm{i}$-line exposure using resists TDMR-AR80 and TDMRAR95 [6519-144]

A. Behrendt, T. Dow, K. Stoeflin, Infineon Technologies Austria AG (USA)

65193K Various factors of the image blur in chemically amplified resist [6519-145]

T. Kawakami, T. Nagai, Y. Nishimura, M. Shima, S. Kusumoto, T. Shimokawa, JSR Corp. (Japan)

65193L Image tone optimization in advanced mask making for DUV lithography [6519-146]

J. Kim, M. Do, S. Jeong, J. Kim, K. Kim, Dongbu Electronics Co., Ltd. (South Korea)

65193N Automatic viscosity controlled production of photoresist [6519-148]

W. S. Chang, C. Monovoukas, Levitronix (USA); M. Tanaka, N. Fronczak, JSR Micro, Inc. (USA)

651930 Photoresist adhesion effect of resist reflow process [6519-149]

J.-M. Park, J.-E. Lee, Hanyang Univ. (South Korea); M.-S. Kim, J.-S. Kim, J.-H. Kim, S.-M. Lee, Seoul National Univ. (South Korea); J.-T. Park, C.-K. Bok, S.-C. Moon, Hynix Semiconductor Inc. (South Korea); S.-W. Park, J.-Y. Hong, H.-K. Oh, Hanyang Univ. (South Korea)

65193T Simulation of the combined effects of polymer size, acid diffusion length, and EUV secondary electron blur on resist line-edge roughness [6519-36]

D. Drygiannakis, Institute of Microelectronics (Greece); M. D. Nijkerk, TNO (Netherlands); G. P. Patsis, G. Kokkoris, I. Raptis, Institute of Microelectronics (Greece); L. H. A. Leunissen, IMEC (Belgium); E. Gogolides, Institute of Microelectronics (Greece) 
$65193 \mathrm{U}$ Distribution control of protecting groups and its effect on LER for EUV molecular resist [6519-47]

D. Shiono, H. Hada, H. Yukawa, Tokyo Ohka Kogyo Co., Ltd. (Japan); H. Oizumi,

I. Nishiyama, ASET NTT. (Japan); K. Kojima, H. Fukuda, Hitachi, Ltd. (Japan)

65193V Evaluation of the 3D compositional heterogeneity effect on line-edge-roughness [6519-154] S. Kang, W. Wu, V. M. Prabhu, B. D. Vogt, E. K. Lin, National Institute of Standards and Technology (USA); K. Turnquest, SEMATECH (USA)

65193W Observing morphology on surface of poly(methacrylate) in ArF lithography using AFM phase image [6519-155]

S. Matsunaga, I. Aratani, F. Okabe, M. Kitayama, Kuraray Co., Ltd. (Japan)

65193X A study of process extension technologies [6519-156]

S.-K. Kim, Catholic Univ. of Korea (South Korea) and Hanyang Univ. (South Korea)

65193Y 32-nm pattern collapse modeling with radial distance and rinse speed [6519-158] J.-S. Kim, W. Chang, S.-W. Park, H.-K. Oh, Hanyang Univ. (South Korea); S.-J. Lee, S.-H. Kim, Samsung Electronics Co., Ltd. (South Korea)

$65193 Z$ The rational design of polymeric EUV-resist materials by QSPR modeling [6519-160] K. Jack, H. Liu, I. Blakey, D. Hill, The Univ. of Queensland (Australia); W. Yueh, H. Cao, M. Leeson, Intel Corp. (USA); G. Denbeaux, J. Waterman, Univ. at Albany (USA); A. Whittaker, The Univ. of Queensland (Australia)

651941 Some non-resist component contributions to LER and LWR in 193-nm lithography [6519-163] T. Kudo, S. Chakrapani, G. Lin, C. Anyadiegwu, C. Antonio, D. Parthasarathy, R. R. Dammel, M. Padmanaban, AZ Electronic Materials USA Corp. (USA)

651942 Depth-of-focus (DOF) and line-width roughness (LWR) performance of novel surface conditioner solutions for immersion lithography [6519-164]

B. J. LU, Y. Huang, H. T. Tseng, C. C. YU, United Microelectronics Corp. (Taiwan); L.-J. Meng, M.-C. Liao, M. Legenza, Air Products and Chemicals, Inc. (USA)

POSTER SESSION: NGL

651943 Effect of photo-acid generator concentration and developer strength on the patterning capabilities of a model EUV photoresist [6519-165]

K.-W. Choi, Intel Corp. (USA); V. M. Prabhu, K. A. Lavery, E. K. Lin, W. Wu, J. T. Woodward, National Institute of Standards and Technology (USA); M. J. Leeson, H. B. Cao,

M. Chandhok, G. Thompson, Intel Corp. (USA)

651944 A study of EUV resist outgassing characteristics using a novel outgas analysis system [6519-166]

J. J. Santillan, M. Toriumi, T. Itani, MIRAI Semiconductor Leading Edge Technologies, Inc. (Japan)

651945 Sub 10-nm contact holes with aspect ratio over sixty formed by e-beam resist shrinkage techniques [6519-167]

W.-S. Chen, M.-J. Kao, M.-J. Tsai, Industrial Technology Research Institute (Taiwan) 
651946 Study on photochemical analysis system for EUV lithography [6519-168]

A. Sekiguchi, Y. Kono, M. Kadoi, Y. Minami, Litho Tech Japan Corp. (Japan); T. Kozawa, S. Tagawa, Osaka Univ. (Japan); D. Gustafson, P. Blackborow, Energetiq Technology, Inc. (USA)

651947 Effect of deprotection activation energy on lithographic performance of EUVL resist [6519-169]

S.-J. Kim, G.-J. Yu, J.-Y. Lee, H.-J. Kim, J.-W. Lee, D.-B. Kim, Y. Kang, J. Kim, Dongjin

Semichem Co., Ltd (South Korea) and Samsung Electronics Co., Ltd (South Korea)

651948 Photoresist dissolution into a $\mathrm{CO}_{2}$ compatible salt and $\mathrm{CO}_{2}$ solution: investigation of processing conditions [6519-170]

A. E. Zweber, North Carolina State Univ. (USA); M. Wagner, Stonelake Research Services (USA); R. G. Carbonell, North Carolina State Univ. (USA)

651949 Exposure of molecular glass resist by e-beam and EUVIL [6519-171]

C. Vannuffel, D. Djian, S. Tedesco, CEA-Leti (France); D. Niakoula, P. Argitis, Institute of Microelectronics (Greece); V. P. Vidali, E. Couladouros, Institute of Physical-Chemistry (Greece); H. Solak, Paul Scherrer Institut (Switzerland)

65194A Sub-10-nm structures written in ultra-thin HSQ resist layers using electron-beam lithography [6519-177]

A. E. Grigorescu, M. C. van der Krogt, C. W. Hagen, Delft Univ. of Technology (Netherlands)

65194B Phenolic molecular glasses as resists for next-generation lithography [6519-192]

X. André, J. K. Lee, A. De Silva, N. Felix, C. K. Ober, Cornell Univ. (USA); H. B. Cao, H. Deng, Intel Corp. (USA); H. Kudo, D. Watanabe, T. Nishikubo, Kanagawa Univ. (Japan)

\section{POSTER SESSION: NOVEL PROCESSES AND APPLICATIONS}

65194C Study on diazonaphthoquinone positive photoresist composition for LCD [6519-172]

F. Zhou, Y. Zou, Z. Zhang, Beijing Normal Univ. (China)

$65194 \mathrm{~F}$ The use of a black pigment polyimide, DARC300, as a light absorber on an optical sensor [6519-176]

K. A. Gehoski, P. M. Holm, K. A. Boggess, Motorola Labs. (USA); C. J. Scott, Brewer Science, Inc. (USA)

Author Index 


\title{
Symposium Committees
}

\author{
Symposium Chair
}

Roxann L. Engelstad, University of Wisconsin/Madison (USA)

Symposium Cochair

Christopher J. Progler, Photronics, Inc. (USA)

Technical Organizing Committees

Executive Committee

John A. Allgair, SEMATECH, Inc. (USA) and Freescale Semiconductors (USA)

Chas N. Archie, IBM Corporation (USA)

Roxann L. Engelstad, University of Wisconsin/Madison (USA)

Donis G. Flagello, ASML US, Inc. (USA)

Clifford L. Henderson, Georgia Institute of Technology (USA)

Michael J. Lercel, SEMATECH (USA) and IBM Corporation (USA)

Harry J. Levinson, Advanced Micro Devices, Inc. (USA)

Qinghuang Lin, IBM Thomas J. Watson Research Center (USA)

Christopher J. Progler, Photronics, Inc. (USA)

Franklin M. Schellenberg, Mentor Graphics Corporation (USA)

Vivek K. Singh, Intel Corporation (USA)

Alfred K. K. Wong, Magna Design Automation, Inc. (USA)

Advisory Committee

Robert D. Allen, IBM Almaden Research Center (USA)

William H. Arnold, ASML Netherlands B.V. (Netherlands)

Timothy A. Brunner, IBM Thomas J. Watson Research Center (USA)

Ralph R. Dammel, AZ Electronic Materials USA Corporation (USA)

Roderick R. Kunz, MIT Lincoln Laboratory (USA)

Harry J. Levinson, Advanced Micro Devices, Inc. (USA)

Burn Lin, Taiwan Semiconductor Manufacturing Company, Ltd. (Taiwan)

Chris A. Mack, LithoGuru.com

Victor Pol, Freescale Semiconductor, Inc. (USA)

Michael T. Postek, National Institute of Standards and Technology (USA)

Luc Van den Hove, IMEC (Belgium)

C. Grant Willson, The University of Texas at Austin (USA)

Anthony Yen, Taiwan Semiconductor Manufacturing Company, Ltd.

(Taiwan) and Cymer, Inc. (USA) 
Downloaded From: https://www.spiedigitallibrary.org/conference-proceedings-of-spie on 26 Apr 2023

Terms of Use: https://www.spiedigitallibrary.org/terms-of-use 


\title{
Conference Committee
}

\author{
Conference Chair
}

Qinghuang Lin, IBM Thomas J. Watson Research Center (USA)

Cochair

Clifford L. Henderson, Georgia Institute of Technology (USA)

Program Committee

George G. Barclay, Rohm and Haas Electronic Materials (USA)

Scott J. Bukofsky, IBM Microelectronics Division (USA)

Sean D. Burns, IBM Thomas J. Watson Research Center (USA)

Ralph R. Dammel, AZ Electronic Materials USA Corporation (USA)

Douglas J. Guerrero, Brewer Science, Inc. (USA)

Christoph K. Hohle, Infineon Technologies AG (Germany)

Nobuyuki N. Matsuzawa, Sony Atsugi Technology Center (Japan)

Dahchung Owe-Yang, Shin-Etsu MicroSi, Inc. (USA)

Kyle Patterson, Freescale Semiconductor, Inc. (France)

Adam R. Pawloski, Affymetrix, Inc. (USA)

Vivek M. Prabhu, National Institute of Standards and Technology (USA)

E. S. Putna, Intel Corporation (USA)

Mark H. Somervell, Texas Instruments Inc. (USA)

Gregory M. Wallraff, IBM Almaden Research Center (USA)

\section{Session Chairs}

1 Invited Session

Clifford L. Henderson, Georgia Institute of Technology (USA)

2 Materials and Processes for Immersion Lithography I

Ralph R. Dammel, AZ Electronic Materials USA Corporation (USA)

Scott J. Bukofsky, IBM Microelectronics Division (USA)

3 Materials and Processes for Immersion Lithography II

George G. Barclay, Rohm and Haas Electronic Materials (USA)

Mark H. Somervell, Texas Instruments Inc. (USA)

$4 \quad$ Resist Materials

Ernisse S. Putna, Intel Corporation (USA)

Ralph R. Dammel, AZ Electronic Materials USA Corporation (USA) 
$5 \quad$ ARC/Multilayer Process

Sean D. Burns, IBM Thomas J. Watson Research Center (USA)

Douglas J. Guerrero, Brewer Science, Inc. (USA)

6 Resist Processing

Kyle Patterson, Freescale Semiconductor, Inc. (USA)

Nobuyuki N. Matsuzawa, Sony Atsugi Technology Center (Japan)

7 Resist Processes and Simulation

Adam R. Pawloski, Affymetrix, Inc. (USA)

Wen-li Wu, National Institute of Standards and Technology (USA)

8 Resist Fundamentals

Vivek M. Prabhu, National Institute of Standards and Technology (USA)

Clifford L. Henderson, Georgia Institute of Technology (USA)

9 LER

Gregory M. Wallraff, IBM Almaden Research Center (USA)

Vivek M. Prabhu, National Institute of Standards and Technology (USA)

$10 \quad \mathrm{NGL}$

George G. Barclay, Rohm and Haas Electronic Materials (USA)

Dahchung Owe-Yang, Shin-Ełsu MicroSi, Inc. (USA)

11 Novel Processes/Applications

Gregory M. Wallraff, IBM Almaden Research Center (USA)

Adam R. Pawloski, Affymetrix, Inc. (USA)

12 Joint Session with Conference 6517 on EUV Resists

Qinghuang Lin, IBM Thomas J. Watson Research Center (USA)

Michael J. Lercel, SEMATECH, Inc. (USA)

Anthony E. Novembre, Lucent Technologies (USA) 


\section{Introduction}

This proceedings volume contains accepted papers from the SPIE Conference on Advances in Resist Materials and Processing Technology XXIV (The SPIE Resist Conference) held as part of the International Symposium on Advanced Lithography from 25 February to 2 March, 2007 in San Jose, California, USA. These proceedings papers cover the latest advances in the chemistry, physics, performance, and processing of resist materials, and offer a glimpse of the stateof-the-art of this important field of semiconductor technology.

This year's SPIE Resist Conference continued the fine tradition of this conference to have a wide international representation and attracted more than 170 oral and poster presentations. These papers are divided into the following categories where $193 \mathrm{~nm}$ immersion lithography and line edge roughness continued to garner tremendous interests among conference attendees.

- Materials and Processes for Immersion Lithography

- Resist Materials

- Resist Processing

- Anti-reflective Coatings and Multi-layer Processes

- Resist Processes and Simulation

- Resist Fundamentals

- Line Edge Roughness

- Resists for the Next Generation Lithography

- Novel Resist Processes and Applications

The Resist Conference also hosted a well-attended joint session on Resists for Extreme UV Lithography with the Emerging Lithography Conference. The two plenary lectures of the Resist Conference discussed some of the most important fundamental issues of chemically amplified resists and emerging resist materials.

It is my great pleasure to announce that the winners of the inaugural SPIE C. Grant Willson Award in Resist Materials are a team of researchers from IBM and ASML. They are G. M. Wallraff, C. E. Larson, G. Breyta, L. K. Sundberg, D. Miller of IBM Almaden Research Center, D. Gill, K. Petrillo of IBM Thomas J. Watson Research Center, and W. Pierson of ASML Nethland B.V. Their paper entitled "The Effect of Photoresist/Topcoat Properties on Defect Formation in Immersion Lithography" covers an important and timely topic in lithography when waterbased 193nm immersion lithography is at the dawn to become a mainstream lithography technology for mass-production of advanced semiconductor chips.

I hope that this proceedings volume will prove valuable to the many resist scientists and engineers working in the fast-moving semiconductor industry. I also hope that it will also serve as a useful reference for those who are interested in 
nanofabrication, micro- and nano-fluidics, micro- and nano-photonics, MicroElectro-Mechanical Systems (MEMS), BioMEMS, organic electronics, advanced packaging as well as bio-chips.

I thank the authors, particularly the two invited speakers, for their valuable contributions to this conference and this proceedings volume. The SPIE Resist Conference is recognized as the premier resist conference among the worldwide resist community simply because the practitioners of resist materials and processes have chosen to showcase their best work at this conference. It is their great work that keeps attracting lithographers from around to the world to make their annual pilgrimage to the SPIE Resist Conference year after year.

I also thank members of the organizing committee for their dedication and hard work to help maintain a high quality of this conference. I am also grateful to Rohm \& Haas Electronics Materials for their generous financial support for the C. Grant Willson Award. Finally, I extend my sincere thanks to the SPIE staff for their tireless efforts and their meticulous organizational skills in helping make this year's SPIE Resist Conference a success and in assembling and publishing this proceedings volume.

Qinghuang Lin 


\title{
Lithography Beyond 32nm - A Role for Imprint?
}

\author{
Mark Melliar-Smith \\ Molecular Imprints, 1807C West Braker Lane, Austin, Texas 78758 \\ mark@molecularimprints.com
}

\begin{abstract}
Imprint lithography has been used since the application of the Chinese wax seal to authenticate official documents. In the past century the resolution of the technology has been driven through commercial applications such as vinyl records, CDs and more recently by high definition DVDs. In the past decade, high resolution imprinting has extended the resolution down to sub $10 \mathrm{~nm}$ features and this fact, coupled with the low cost of the tool, make it attractive as an alternative to other lithographic technologies.

More recently the evolution of imprint lithography from thermal imprinting to UV cured materials, has allowed the technology to operate at room temperature (allowing tight overlay) and low material viscosities (important for high throughput), opening up the potential for CMOS applications. This paper will discuss recent progress in align/overlay, throughput, defect density, materials and the availability of sub $20 \mathrm{~nm}$ templates, along with tool developments, that make the technology a viable option for advanced CMOS beyond $32 \mathrm{~nm}$ HP design nodes.

In addition, imprint lithography is being developed for other large electronic markets such as bit patterned media (BPM) for disk drives, and photonic crystals to increase the brightness and efficiency of LEDs used for solid sate lighting, both of which applications are likely to go into production ahead of sub $32 \mathrm{~nm}$ CMOS. Since overlay requirements are significantly less, whole wafer (as opposed to step and repeat) imprinting is used for these applications, and the presentation will discuss the synergies with CMOS imprint technology.
\end{abstract}

Key words: Imprints lithography, photolithography, bit patterned media, photonic crystals,

\section{Introduction}

Despite the remarkable progress made in the past decade in extending optical lithography to deep subwavelength imaging, the limit for the technology seems to be fast approaching. At $22 \mathrm{~nm}$ half pitch design rules, neither very high NA tools (NA 1.6), nor techniques such as double patterning, are likely to be sufficient. The extension of photon based systems to EUV remains very challenging, and this has opened up the opportunity for imprint lithography as a very viable NGL alternative.

Small feature imprint lithography has existed for several years. ${ }^{(1-7)}$ The original technique involved the use of a patterned template which is impressed onto a thermo plastic material and, with the combination of heat and pressure, the pattern in the template was transferred to the substrate.$^{(2)}$ Compact disks were one of the early applications for the technology. Recently the technique has been significantly improved with the development of Step and Flash Imprint Lithography $\left(\mathrm{S}_{-} \mathrm{FIL}^{\mathrm{TM}}\right) \cdot{ }^{(1)}$ This technique was invented by Professors Grant Willson and SV Sreenivasan at the University of Texas, and involves deposition of a low viscosity monomer on the substrate, lowering a template into the fluid which then flows into the patterns of the template. Following this fill step, the monomer is exposed to UV light to cross-link it and convert it into a solid, and the template is removed leaving the solid pattern on the substrate. ${ }^{(1,3)}$ The advantages of this development (low pressure imprinting, low viscosity template filling and room temperature operation) make it uniquely capable for CMOS applications. Although this paper, and this conference, are largely focused on CMOS, it is worth noting that imprint technology can also be used in a wide variety of other advanced applications, many of which are only commercially viable given the availability of low cost (sub \$2M) tools capable of delivering sub $50 \mathrm{~nm}$ features. These applications include the use of photonic bandgap crystals to 
enhance LED efficiency and brightness, patterned media for disk drives, polarizers for projection optical engines and a wide variety of other electronic and photonic devices. For most of these applications the capital cost of $193 \mathrm{~nm}$ immersion lithography is commercially untenable, even assuming that the required resolution limits could be reached.

The purpose of this paper is to describe the recent advances in imprint lithography with particular reference to its application for silicon integrated circuits.

\section{Imprint Technology for CMOS Applications}

The S-FIL process is shown schematically in Figure 1. The process starts with a template made from a standard 6025 photomask blank, with the pattern etched into the glass using the same technology that is used for phase shift masks. An array of pico-liter sized drops of a low viscosity monomer, are spread across the field being imprinted and the template lowered onto the drops. When the surface tension of the liquid has been broken, capillary action draws the fluid into the template features. Once filling is complete, ultraviolet light, passing through the glass template, is used to cross link the monomer and convert it to a solid. The template can then be withdrawn and the process repeated on the next field.

The use of a low viscosity liquid has several advantages over spin-on films. Firstly, the lower viscosity of the liquid means that material movement and filling of the template are faster, particularly since the drop pattern density can be matched to the pattern density on the template. Secondly the process is intrinsically lower pressure - in fact controlled by capillary action, which also assures that the fluid does not spread outside of the template field. Finally, the use of the "drop on demand" technique prevents the requirement that spin coated wafers be passed into the tool - avoiding the problems of materials evaporation, particle collection on "wet" wafers and the need for a linked track. Since the pattern is "fixed" by UV light, the whole process can be completed at a controlled temperature allowing tight overlay between levels.

Molecular Imprints has commercialized the S-FIL technology, offering a CMOS compatible imprint tool the Imprio- $250^{\mathrm{TM}}$ - which has been designed to take advantage of this type of imprint lithography, and offers the capability of mix and match with $193 \mathrm{~nm}$ optical lithography with a $26 \mathrm{~mm} \times 33 \mathrm{~mm}$ field size, alignment/overlay and magnification control, automated imprint and FOUP to FOUP wafer handling. A photograph of the Imprio-250 is shown in Figure 2.

\section{The Advantages and Challenges for Imprint Lithography}

Imprint lithography has a number of distinct advantages over photolithography when used for CMOS applications. These include:

(i) Lithographic capability

The imprint process appears to perfectly replicate the template. In consequence the template controls the resolution, line edge roughness and CD control of the imprinted pattern. Since the template has to be only written once, great care can be taken to assure its fidelity. Resolution limits appear to be less than $5 \mathrm{~nm}$. An example of research work from the University of Illinois ${ }^{(7)}$ is shown in Figure 3, where a carbon nano-tube based template was replicated - if not perfectly. Since the monomer is of low molecular weight and is physically constrained by the template during solidification, there are none of the resolution/LER issues of molecular size, acid diffusion or areal image that are present in optical lithography. Other data/examples of lithographic quality are shown in Figures $10,12 \& 13$ and are discussed later in the text. 
Since the template is faithfully replicated by the imprint process - topics such as OPC and MEEF have no meaning in imprint lithography. While manufacturing a $1 \mathrm{x}$ template does present some additional challenges - it provides the device designer with complete freedom to design circuits without any lithography based design rules, freeing the designer from optical modeling artifacts. It is truly a "what you see is what you get" technology.

(iii) Lower capital cost

Since imprint tools lack the very complex lens and mirror systems inherent in photon based technologies, nor the need for a linked track, nor the requirement for vacuum and complex sources in EUV, the cost of the tools are significantly less than their competition. In addition, since they are largely mechanical tools, the build times are markedly less.

(iv) $\quad 3 \mathrm{D}$ printing

Since multi-level or curved features can be built into the templates, the technology has the capability for three-dimensional printing. This has the potential to extend the technology well beyond simple resist and etch capability and into the realm of single step imprinting of dual damascene structures (multilevel features) or direct imprinting of micro-lenses for CMOS imagining devices (curved features). These applications will be discussed later in the paper.

However, as might be expected, these advantages also come with a set of companion challenges. Confronting the technical challenges listed below is the topic of the main portion of this text, but they are listed below in summary form and to provide balance to the advantages.

(i) $1 \mathrm{x}$ templates - higher resolution, image placement and defect requirements as compared to $4 \mathrm{x}$ photomasks

(ii) Defect concerns - near contact printing

(iii) Throughput - in contrast to photolithography that simply requires exposure for each field, imprint requires not only exposure, but also material dispense, template fill, and field by field alignment.

(iv) Overlay - issues of mechanical magnification control

\section{Technical Progress in Imprint Lithography for CMOS Applications}

\subsection{Templates}

Imprint lithography uses templates made with commercial photomask materials and processes. This is a significant advantage relative to previous NGL technologies (X-Ray Proximity and Electron Beam Projection) that struggled with membrane based masks, or even EUV that requires new substrates and reflecting metal films. However, the $1 \mathrm{X}$ requirement does test resolution related issues - although not as near to the $4 \mathrm{X}$ that might come to mind. The advent of OPC features, which will soon be no more than $1.3 \mathrm{x}$ the minimum feature size on the wafer ${ }^{(8)}$ are accelerating the resolution of mask ebeam writers. In addition for imprint templates, since the chrome is only being used as an etch mask (no optical opacity requirements), it is possible to use thinner chrome and ebeam resist than is typical to push resolution down to the required 1x. Image placement is also an issue for a $1 \mathrm{x}$ technology, but again, the approaching application of double patterning for $193 \mathrm{~nm}$ immersion is pressing the existing photomask industry to meet very tight image placement specifications, even for nominally $4 x$ photomasks. 
Using commercially available VSB mask writers, imprint templates are already being written down to $35 \mathrm{~nm}$ dimensions, with very high quality, as shown in Figure $4 \mathrm{a}^{(9)}$. For higher resolution applications, imprint templates can be written with variants of ebeam direct write tools, ${ }^{(10)}$ usually Gaussian Beam systems. These tools have unparalleled resolution, and can easily produce templates with dimensions of less than $20 \mathrm{~nm}$ as shown in Figure $4 \mathrm{~b}^{(11)}$ providing an imprint resolution capability well beyond that possible with existing optical technologies.

However resolution is not the only issue for ebeam pattern generators, although it is the most compelling one for device/process development engineers pushing down below 30nm. Photomask write times have been rising rapidly in the past few years - victims of the huge data files required for advanced OPC. Templates have certain advantages in this area. Firstly there are no OPC features required, significantly reducing the number of shots required, and secondly, the area to be written is also a lot smaller. In addition, it is possible to "replicate" template patterns. In this process a single die template is made using an ebeam pattern generator, and then an imprint tool, such as the Imprio-250, is used to replicate this die to create a full field template containing multiple die. For a high volume runner, with four die per field and requiring five mask sets, the effective ebeam write acceleration would be a factor of 20 (four die X five mask sets). This technique has been used in the past for whole wafer, non-CMOS, imprint applications, and an example of the efficacy of the replication process is shown in Figure 5. The potential for lowering write times for imprint templates is important since it opens up the potential to use less sensitive ebeam resists to make the templates. This in turn allows templates with superior line edge roughness and higher resolution.

Template inspection and repair is also an issue since printable features are four times smaller than those for photomasks. To date the most sensitive template inspection techniques have used $1 \mathrm{x}$ wafer inspection tools. The KLA ES-32 tool has proved to be effective ${ }^{(12)}$ in detecting sub $50 \mathrm{~nm}$ defects using a die to die approach as shown in Figure 6a. For die to data base results, NGR ${ }^{(13)}$ has been able to detect $20 \mathrm{~nm}$ defects using its 2100 tool, as shown in Figure 6b. Repair of template defects can either be completed by mechanical removal of excess material ${ }^{(14)}$ using a Rave $650 \mathrm{NM}$ tool, or by replacing missing material using a Nowatech MeRiTMG ebeam ${ }^{(15)}$ enhanced deposition system. Examples of repair are shown in Figure 7. In the case of imprinting, the repairs are required to fill or remove material to a particular thickness, in contrast to a particular optical opacity. Small variations away from the nominal required dimensions are acceptable since this would simply mean that the imprinted resist thickness was slightly different from nominal.

\subsection{Alignment and Overlay}

All imprint tools for CMOS applications must be designed to mix and match with existing $193 \mathrm{~nm}$ optical lithography tools. This requires a step and repeat tool with a $26 \mathrm{~mm} \times 33 \mathrm{~mm}$ field size, alignment marks that fit into $75 \mu \mathrm{m}$ streets, alignment systems with sufficient contrast and show overlay results on top of $193 \mathrm{~nm}$ printed under-layers.

The Imprio-250 uses a field by field alignment system, originally conceived for use in X-ray proximity printing, an earlier NGL technology. ${ }^{(16)}$ This does not add to the imprint time since the alignment occurs during the time that the fluid is filling the template features. The "in liquid" align has the advantage that the imprint fluid acts both as a vibration damper and also a lubricant to facilitate the small motions required between the template and the substrate during alignment, reducing stiction effects.

Since the template and substrate are in close proximity $(<10 \mu \mathrm{m})$ during the alignment process, it is practical to capture the relative positioning error between two matching alignment marks using a Moiré image based technique ${ }^{(16,17)}$. The advantage of using a $1^{\text {st }}$ order Moiré image based technique is that it can provide high resolution alignment data using a low NA imaging unit $(<0.05)$ without blocking the UV beam path. The alignment system utilizes multiple imaging units that can capture not only $\mathrm{x}, \mathrm{y}$, theta but also magnification errors. Utilizing the gap insensitiveness of the $1^{\text {st }}$ order Moiré ${ }^{(16,18)}$ alignment data can be captured throughout the template fill step and corresponding correction motions are accomplished in a 
parallel manner. This system has demonstrated better than $1 \mathrm{~nm}$ sensitivity of the alignment and positioning system. ${ }^{(16,18)}$

Magnification correction is achieved by mechanically compressing the template. Positive magnification can be achieved by writing the template $5 \mathrm{ppm}$ oversize and releasing the compression. In this way the required $+/-5 \mathrm{ppm}$ can be obtained. Since the distortion is this small, well within the elastic regime of the material, it is perfectly reversible. A multi-point forcing mechanism was developed ${ }^{(19)}$ that can induce optimized vectors of correction forces along the periphery of the template. Such an optimized forcing vector for the $\mathrm{mag} /$ distortion correction is computed using multiple relative position data between the template and the wafer that are captured using the alignment system described above. When n-points of forcing per template side are utilized, a vector with a $4 n-3$ controllability, where 3 stands for three constraints, is available. Therefore, a typical alignment for $\mathrm{x}, \mathrm{y}$, theta, mag $\mathrm{x}, \operatorname{mag} \mathrm{y}$ and orthogonality can be compensated.

The efficacy of the alignment and magnification control systems were tested using a KLA overlay tool and AIM/Archer alignment marks. A sample set of results ${ }^{(20)}$ are shown in Figure 8 with approximately $20 \mathrm{~nm} 3$ sigma overlay measured for 32 fields and 81 points per field. The major sources of the error are thought to be from thermal distortions, placement errors on the template and image field distortions from the $193 \mathrm{~nm}$ scanner. Further improvements are expected to reduce the overlay errors down to $5 \mathrm{~nm}$.

\subsection{Throughput}

While slower throughputs may be acceptable for early unit process development and device prototyping, it is clear that production needs of $20 \mathrm{wph}$ are required almost regardless of cost of ownership. This represents a challenge for imprint, since it is a multi-step process (fill, overlay, cure etc). The required budget to imprint a field at $20 \mathrm{wph}$ is shown in Table 1.

Table 1 - Field by Field Time Budget for 20wph (100 fields/300mm wafer)

Stage move, fluid dispense time

Alignment, template fill time

UV cure time

Separation time

TOTAL
0.15 seconds

1.00 seconds

0.15 seconds

0.10 seconds

1.40 seconds

The most significant budget item, and the one specific to imprint, is the time required to fill the template. The two key parameters for fast fill are firstly, drop size and placement and secondly, the template contact angle to minimize any trapped air bubbles. In this latter respect, care must be taken to lower the template in a controlled and inclined angle such that the drops coalesce in a wave front that allows the gas between the drops to be swept out rather than trapped between the drops. The size and placement of the drops are carefully controlled to facilitate this. To do this, the drops, with a size of a few pico-liters, are dispensed using a linear array of several hundred inkjet nozzles that sweeps across the $26 \times 33 \mathrm{~mm}$ field. The density and pattern of the drops are automatically slaved to the GDS-II file used to create the template, such that the density of the drops is optimized to the template pattern to minimize the amount of material movement required to fill the template features. Under optimal conditions fill times as low as 3 seconds have been achieved in the laboratory and further improvements are expected. The viscosity of the imprint fluid is also an issue relative to fill times. Acrylate based materials (see Section 5.1 below) have viscosities in the 5$10 \mathrm{cps}$ range, and other materials such as vinyl ethers are closer to $1 \mathrm{cps}$.

Future tool designs could use two other advantages inherent to imprint to improve the throughput. The ability to imprint larger field sizes could allow future systems to print four $26 \mathrm{~mm} \times 33 \mathrm{~mm}$ fields at once. This would place significant additional requirements on the template fabrication and overlay, but quadruple the throughput. In addition, since the cost of the imprint heads is minimal relative to optical lens stacks, multiple heads could be placed on a single stage platform, further increasing throughput, although multiple templates would be needed. 


\subsection{Defects}

There is concern about the defect levels inherent in imprint lithography since it is a near contact technology. However, it is an error to assume that the problem is similar to that of contact printing for the following reasons:

(i) The template never actually touches the substrate. There is always a thin residual film of imprint material between the two surfaces.

(ii) The imprint fluid drops, which have micron height, tend to cushion any impact between the template and particles

(iii) The template is made from fused silica - a hard and robust material.

Significant progress has been made in reducing the defectivity of CMOS imprints. This progress is shown in Figure 9. ${ }^{(21)}$ While still a considerable distance from what is ultimately needed for CMOS production, the progress has been sufficient for early device development activities. A Pareto analysis shows the defects to have three major sources: template defects, imprint specific defects and particles.

Template defects, as supplied by the commercial photomask vendors are, as might be expected, typically less than $1 \mathrm{~cm}-2$ as measured on a KLA 576 inspection tool. The template defect level is increased somewhat by the post photomask processing specifically required for templates (dice and polish, mesa preparation) but this does not represent an insuperable problem. The major challenge is to extend the life of the templates prior to their need to be removed from the imprint tool and re-cleaned. The templates do not "wear-out" since the fused silica is not eroded in anyway by contact with the imprint fluid. However, they can, over time, pick-up defects from partially cured monomer, or other contaminants, after several thousand imprints and need to be cleaned. Since the monomer is organic, the cleaning process is a standard oxidative clean, and early results for in-situ gas phase cleaning show some promise.

Imprint specific defects (micro-bubbles, imprint feature pull-outs etc) have been reduced to $\sim 1 \mathrm{~cm}-2$. One important piece of data further suggests that these defects are not very dependent on defect size. A sample of imprinted patterns was tested on a KLA 2132 optical inspection tool with a $200 \mathrm{~nm}$ pixel size and then retested on a KLA ES32 electron beam tool with a $25 \mathrm{~nm}$ pixel size. The comparison of the results is shown in Table 2.

Table $2-200 \mathrm{~nm}$ and 25nm Pixel Inspection Results

$\begin{array}{lcr} & \begin{array}{c}\text { KLA 2132 } \\ (200 \mathrm{~nm})\end{array} & \begin{array}{c}\text { KLA ES32 } \\ (25 \mathrm{~nm})\end{array} \\ & & \\ \text { Template defects } & 4.8 \mathrm{~cm}-2 & 6.0 \mathrm{~cm}-2 \\ \text { Particles } & 2.4 \mathrm{~cm}-2 & 19.7 \mathrm{~cm}-2 \\ \text { Imprint specific defects } & 0.0 \mathrm{~cm}-2 & 0.0 \mathrm{~cm}-2\end{array}$

Although this was an experiment with relatively low inspected area, the lack of defect size dependence for both the template defects and the imprint specific defects is very important since it suggests that the density of these defects is not strongly correlated with size. This is not altogether surprising when considered more deeply. For example micro-bubbles are know to be less stable the smaller they become, and imprint feature pull outs are more dependent on aspect ratio than feature size. The increase in particles as the resolution of the defect detection improved was to be expected. Further work in a cleaner environment, will reduce these numbers.

\section{Materials and Processes}

For imprint lithography to be successful in CMOS, a complete solution must be available including materials and processes to complement the tool and templates. 


\subsection{Materials}

Successful imprint materials must be formulated with consideration for many requirements and the resulting formulations tend to be very sophisticated ${ }^{(22)}$ to meet the severe yield demands for CMOS. The majority of the work described below is built around an acryate backbone, but vinyl ethers ${ }^{(23)}$ have also been used.

One of the most basic challenges for imprint lithography is how to assure that the material sticks to the substrate and not to the template, even after many thousands of imprints. To reduce the surface energy of the template, a high surface concentration of fluorine is required, but this then restricts the wettability and filling speed, requiring a delicate balance. In addition, any coating on the template is liable to wear and tear, and an in-situ replenishment/repair process is required to keep the defectivity levels down. On the wafer surface, an adhesion promotion film can be used, but needs to be very thin $(<2 \mathrm{~nm})$ and must be formulated to assure adhesion to multiple surface materials and also with a mind to wettability.

The cross linked material has to be drawn out of the template features during separation. This mandates a material with adequate mechanical strength, toughness and Young's Modulus to maximize the aspect ratio that can be used and yet completely prevent the possibility of a feature being left in the template. Adding polar components helps with these properties but excessive amounts increases the surface tension and reduces the fill speed. The etch resistance must be equivalent to the photoresists. The material must be formulated to be sensitive to UV radiation to assure fast curing, which means attention must be paid to the photoiniators, the wavelength of the exposing light and the prevention of oxygen inhibition.

Viscosity must be controlled. Low viscosities $(<5 \mathrm{cps})$ assist faster feature filling, ${ }^{(24)}$ but higher viscosities $(10-20 \mathrm{cps})$ tend to be more favorable for ink-jet dispense into pico-liter drops. Lower viscosity materials tend to have high vapor pressures and evaporation rates which need to be minimized or compensated for.

Finally the purity of the material must meet the stringent CMOS requirements of $<10 \mathrm{ppb}$ (metal ions), not just as formulated, but after passage through the inkjet head assembly.

\subsection{Process}

For imprint to be successful for CMOS, the tools must not only mix and match with $193 \mathrm{~nm}$ optical tools, but the imprint materials and processes have to be compatible with the upstream and downstream CMOS processing as well. Most CMOS customers want to place the imprint process into their integrated process without any changes - essentially a drop in replacement for optical lithography.

This has been achieved with the use of the SFIL-O process shown in Figure 1. In this process the organic imprint material has been formulated to be an effective etch mask for silicon based films, and the imprint process tuned to the point where the residual organic layer between the imprinted features is both very thin $(\sim 15 \mathrm{~nm})$ and very uniform $(<5 \mathrm{~nm} 3 \sigma)$. Since the imprinted features have a typical height of over $50 \mathrm{~nm}$ (2.5:1 aspect ratio for $22 \mathrm{~nm}$ HP features), the residual layer can be removed with a quick "de-scum" oxygen etch, prior to etching the hard mask with a fluorine based etch. Typical results for hard mask etching are shown in Figure 10. ${ }^{(25)}$ Excellent resolution, line edge roughness and sidewall angle are routinely achieved. Typical etch ratios between the imprinted material and the underlying hard mask are designed to mimic $193 \mathrm{~nm}$ photoresists, so that the etching processes can be very similar.

An alternative process called SFIL- ${ }^{(26)}$ has been developed to provide a positive image of the template on the substrate (as opposed to the negative working SFIL-O process). In this case, following imprinting, a silicon containing film is spun on top of the imprinted features, effectively planarizing the surface. A blanket etch back of the silicon film is made until the imprinted organic features are exposed. At this point the etch chemistry is changed to an oxidative etch which then removes the underlying imprinted features, but leaves the silicon containing material between them intact to act as an etch mask. The SFIL-R process has the advantage of being less sensitive to surface topography on the substrate. 
Imprinting has a unique advantage over photolithography, in that one can make multilevel template features. There has been growing interest in the use of multi-level template imprinting to define both levels of a dual damascene pattern with a single step. ${ }^{(27)}$ This can be done in one of two ways. In the first case, a deposited low-k film is patterned with a double level template to pattern both the via and channel features with an imprinted resist. This resist pattern is then etched down to replicate the pattern in the low-k material. This requires that the resist and low-k film etch at the same rate, but surprisingly good results have been achieved. ${ }^{(28)}$ Given the large number of metal levels on advanced logic devices, this offers the potential for significant reduction in cost, and at feature sizes that may be more compatible with $1 \mathrm{x}$ template technology. An even greater cost reduction can be achieved, if the low-k material is directly imprinted in one step. This presents many challenges for the material - which must now not only be a viable imprint material but also a viable low-k material as well. However, significant progress has been made in this area, both in terms of material ${ }^{(29,30)}$ and process ${ }^{(29)}$ as shown in Figure 11.

\section{Application of Imprint to CMOS}

As mentioned at the start of this paper, the most likely production entry point for imprint in CMOS will be at or below the $32 \mathrm{~nm}$ half pitch node. While the production ramp date for these technology nodes will be out into the next decade, R\&D engineers are beginning to require sub $32 \mathrm{~nm}$ lithography for unit process development (UPD) and device prototyping. This is an excellent application for imprint lithography since sub $32 \mathrm{n}$ resolution is easily obtained, the SFIL-O process is fully compatible with existing hard mask etch processes, and the absence of liquid development means that pattern collapse is not an issue. Examples of CMOS UPD patterns are shown in Figure 10. ${ }^{(25)}$

Further extensions to device prototyping require capability for overlay in addition to resolution. For example, IBM recently announced results ${ }^{(31)}$ on device designs that require densities down to $10 \mathrm{~nm}$ HP for economic feasibility. Progress with imprint lithography has allowed device structures to begin approaching these dimensions as shown in Figure 12. ${ }^{(32)}$ The $27 \mathrm{~nm}$ silicon fin structures, built on an SOI substrate, were patterned using SFIL-O imprint lithography, followed by plasma etching with a SiN hardmask. The etched cross sections illustrated in Figure 12, show excellent line edge roughness, CD control and sidewall angles for the etched silicon fins.

Unlike other CMOS NGL technologies, imprint lithography is also applicable to other markets which have similar resolution demands as CMOS, but are likely to go into volume production at an earlier date. One example ${ }^{(33)}$ is bit patterned media (BPM) for hard disk drives. This technology, expected to ramp at the end of this decade, is required since magnetic confinement of the domain is inadequate below $20 \mathrm{~nm}$ ( $>500 \mathrm{~Gb} / \mathrm{sq}$ inch density), and beyond this requires the magnetic domains to be individually etched into the magnetic film on the disk. An example is shown in Figure 13. ${ }^{(34)}$ Imprint is the preferred solution for this application given the lower cost and ability to print larger fields (up to 3.5" disks) when compared to photolithography. With over a billion disk drives produced each year, this market alone will be hundreds of tools. The early application to BPM at $20 \mathrm{~nm}$ will help develop the commercial infrastructure for templates, materials and process technology.

A second non-CMOS market is patterning high brightness LEDs with photonic crystals. These structures look like arrays of contact holes on the surface of the LED and serve to increase both the brightness and the efficiency of the LED. ${ }^{(35)}$ The feature sizes need to be less than the wavelength of the LED emission, and the minimum hole spacing can be significantly less than $100 \mathrm{~nm}$. Given the poor surface flatness, and 3" dimensions, of the GaN substrates used for these devices, optical lithography is difficult to use for these dimensions, and imprint lithography is the preferred solution. Photonic crystal enhanced LEDs are beginning to appear in commercial ${ }^{(36)}$ quantities and with broad markets such as back lit flat panel displays, architectural lighting and automotive headlights, this application will also require large numbers of imprint tools over the next five years.

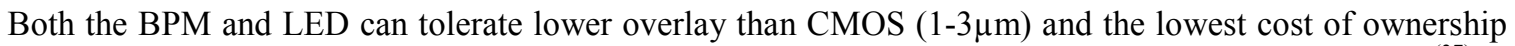
comes from printing the whole substrate at once. Molecular Imprints has developed a companion tool ${ }^{(37)}$ to the I-250, the I-1100 shown in Figure 14, to handle whole wafer imprinting. Like the I-250, the I-1100 is a 
fully automated, cassette to cassette manufacturing tool, but uses a thinner, compliant template to allow for the greater non-flatness of the non-silicon wafers.

\section{Summary}

Imprint lithography has made remarkable improvements over the past five years. The advent of drop on demand, step and flash technology has resulted in significant improvements in overlay, defect density and throughput, such that this technology is now a very viable contender for CMOS NGL. Concurrent improvements in template fabrication, materials and process mean that the technology can be used as a drop in replacement for photolithography but at much higher resolutions and lower cost than competing technologies such as EUV.

\section{Acknowledgements}

The authors would like to thank the many members of Molecular Imrpints and other companies who provded data for this paper. This work was partially funded by DARPA Contract No. N66001-02-C-8011, NIST Advanced Technology Program Contract No. 70NANB4H3012, and DoD Contract No. N66001-06C-2003.

\section{References}

1. Colburn, M., Johnson, S., Stewart, M., Damle, S., Bailey, T., Choi, B.J., Wedlake, M., Michaelson, T., Sreenivasan, S.V., Ekerdt, J., and Willson, C.G., Proceedings of the SPIE's Int. Symp. on Microlithography, Vol. 3676, pp. 379-389, March 1999.

2. S.Y. Chou, P.R. Krauss, P.J. Renstrom, "Nanoimprint lithography," J. Vac. Sci., Tech. B, 1996. 14(6).

3. M. Bender et al., Microelectronic Engineering, 61- 62 (2002), pp. 407-413.

4. Ian McMackin, Philip Schumaker, Daniel Babbs, Jin Choi, Wenli Collison, S.V. Sreenivasan, Norman Schumaker, Michael Watts, Ronald Voisin, Proc. of the SPIE's Int. Symp. on Microlithography: Emerging Lithographic Technologies VII, Santa Clara, CA, February 2003.

5. D.J.Resnick, W.J.Dauksher, D.Mancini, K.J.Nordquist, S.Johnson, N.Stacey, J.G.Ekhert, C.G.Willson, S.V.Sreenivasan and N.Schumaker, J.Vac. Sci. Tech B, 21, p 2624, November 2003

6. D.J.Resnick, D.P.Mancini, K.J.Norquist, W.J.Dauksher, I.McMackin, P.Schumaker, E.Thompson and S.V.Sreenivasan, J. Microlith, Microfab and Microsystems, 3, p316 April 2004.

7. F.Hua, Y.Sun, A.Gaur, M.A. Meitl, L.Bilhaut, L.Rotkina, J.Wang, P.Geil and J.A.Rogers, Nano Letters, 4, 2467 (2004).

8. International Technology Roadmap for Semiconductors - 2006 Update - Table 78a "Optical Mask Requirements"

9. G. M. Scmid, E. Thompson, N. Stacey and D. Resnick, SPIE Emerging Lithographic Technologies Symposium, Feb 2007

10. See www.vistec-semi.com for more details

11. G. M. Schmid, E. Thompson, N. Stacey, D. J. Resnick, D. L. Olynick and E. H. Anderson, Microlelectronic Engineering, to be published (2007).

12. S. V. Sreenivasan, P. Schumaker, I. MaMackin and J. Choi, $5^{\text {th }}$ International Conference on Nanoimprint and Nanoprint Technology, Nov 2006

13. L. J. Myron, E. Thompson, I. McMackin, D. J. Resnick, T. Kitamura, T. Hasebe, S. Nakazawa, T. Tokumoto, E. Ainley, K. Nordquist, W. Dauksher; Proc SPIE Vol 6151, page 173 (2006).

14. W. Dauksher, K. Nordquist, N. V. Le, K. Gehoski, D. Mancini, D. J. Resnick, R. Bozak, R. White, J. Csuy and D. Lee, J. Vac. Sci Technology (2004), 3306.

15. G. M. Schmid, D. J. Resnick, R. Fettig, K. Edinger, S. R. Young and W. J. Dauksher, European Mask and Lithography Conference, January 2007.

16. Euclid E. Moon, et al; 2648 J. Vac. Sci. Technol. B 13(6), Nov/Dec 1995 
17. B.J. Choi, et al; SPIE Intl. Symp. Microlithography: Emerging Lithographic Technologies, 2001 Santa Clara, CA.

18. Euclid E. Moon, et al; J. Vac. Sci. Technol. B, Vol. 21, No. 6, Nov’Dec 2003

19. Jin Choi, et al, Microelectronic Engineering, 2004 V78-79, p633

20. P. Schumaker, T. Rafferty, J. Choi, I. McMackin and A.DiBiase, SPIE Intl. Symp. Microlithography: Emerging Lithographic Technologies, Poster Session 2006

21. I. McMackin - private communication

22. F. Xu, N. Stacey, M. Watts, V. Truskett, I. McMackin, J. Choi, P. Schumaker, E. Thompson, D. Babbs, S.V. Sreenivasan, G. Willson and N. Schumaker; Proceedings of SPIE Volume 5374, No. 1, pp. 232-41, 2004, Santa Clara, California, USA

23. E. K. Kim, N. A. Stacey, B. J. Smith, M. D. Dickey, S. C. Johnson, B. C. Trinque, C. G. Willson, J. Vac. Sci. Technol. B 22(1), Jan/Feb 2004, pp. 131-135

24. S. Reddy, R. T. Bonnecaze, Microeletronic Engineering, 82 (2005), pp. 60-70

25. I. McMackin and D. LaBrake - private communication.

26. S. V. Sreenivasan, I. McMackin, F. Xu, D. Wang, N. Stacey and D. J. Resnick, MICRO Magazine, January 2005.

27. M.D.Stewart et al, SPIE Intl Symp Microlithography Conference, March 2005, Paper 5751-21

28. G. Willson - to be published

29. G. Willson et al, SEMATECH Litho Forum, May 2006, Vancouver, Canada.

30. R.Sooriyakumaran et al, SEMATECH Litho Forum, May 2006, Vancouver, Canada.

31. K. Gopalakrishnan et al, IEDM Tech. Digest 2005, p 471; R. S. Shenoy et al, Proc Symp VLSI Tech, June 2006, p 140. and Y. C. Chen et al, IEEE Electron Device Meeting, December 2006.

32. M. Hart et al, DARPA presentation January 22, 2007

33. Z. Z. Bandic, E. A. Dobisz, T-W. Wu and T.R.Albrecht Soild State Technology Supplement Sept 2006

34. D. J. Resnick, G. M. Schmid and M. Miller MRS Proc Nov 2006; D. J. Resnick, G. M. Schmid, M. Miller, G. F. Doyle, C. Jones and D. LaBrake; Solid State Tech Feb 2007.

35. J. J. Wierer, M. R. Krames, J. E. Epler. N. F. Gardner, J. R. Wendt, M. M. Sigalas, S. R. J. Brueck, D. Li and M. Shagam, Proc SPIE (2005) 5739, 103.

36. R. Karlicek, Strategies in Light Symposium (San Jose), February 2007.

37. For more data on the Imprio-1100 see www.molecularimprints.com 


\section{Figures}

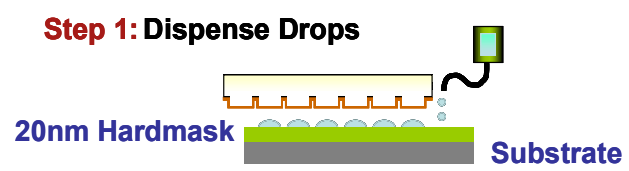

Step 2: Lower Template and Fill Pattern

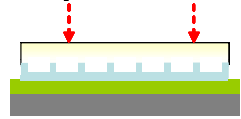

Step 3: UV Polymerize Imprint Fluid

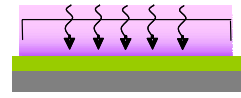

Step 4: Separate Template from Substrate

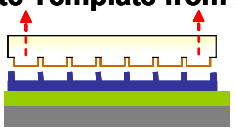

Figure 1. Schematic of the SFIL-O process
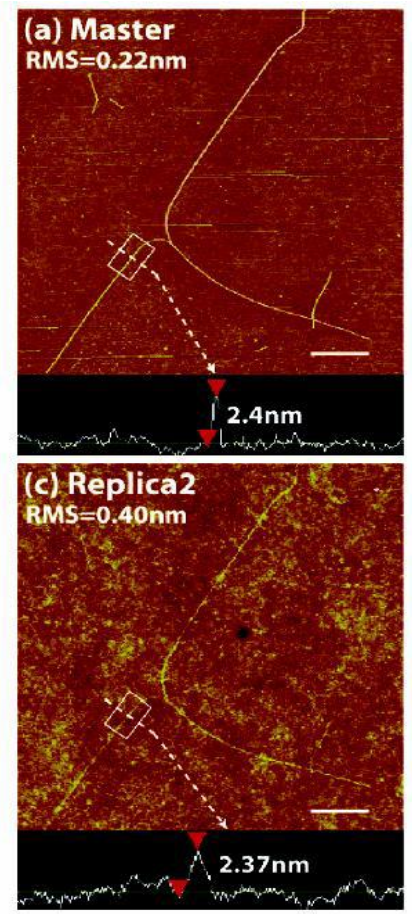

Figure 3 UV cured imprints showing sub $5 \mathrm{~nm}$ resolution. Top micrograph is the template, lower micrograph the imprinted image. From ref 7.

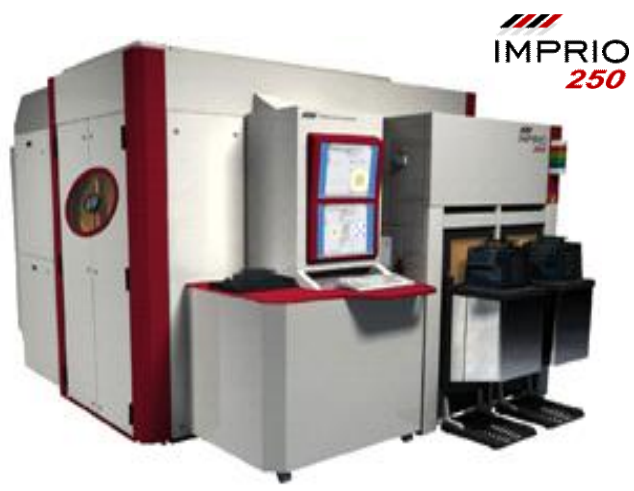

Figure 2 Imprio-250 tool for CMOS

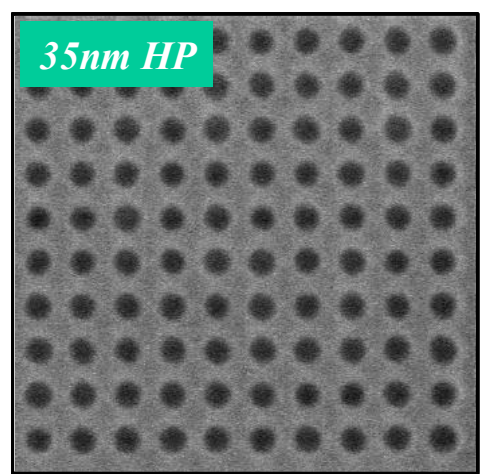

Figure 4a

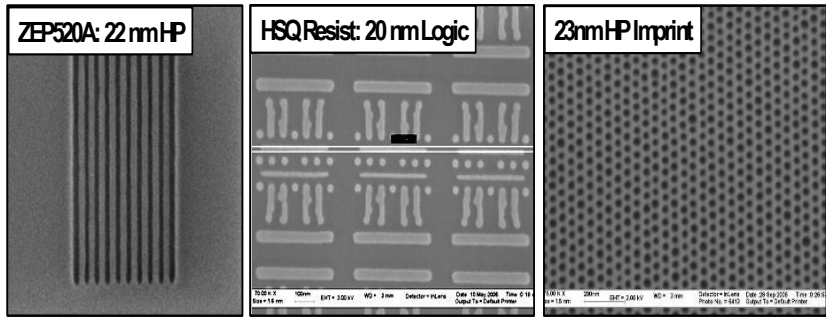

Figure $4 \mathrm{~b}$

Figure 4 showing $1 \mathrm{x}$ template patterns.

Top micrograph from VSB pattern generators Lower micrographs from Gaussian Beam tools From ref 9 and 11 

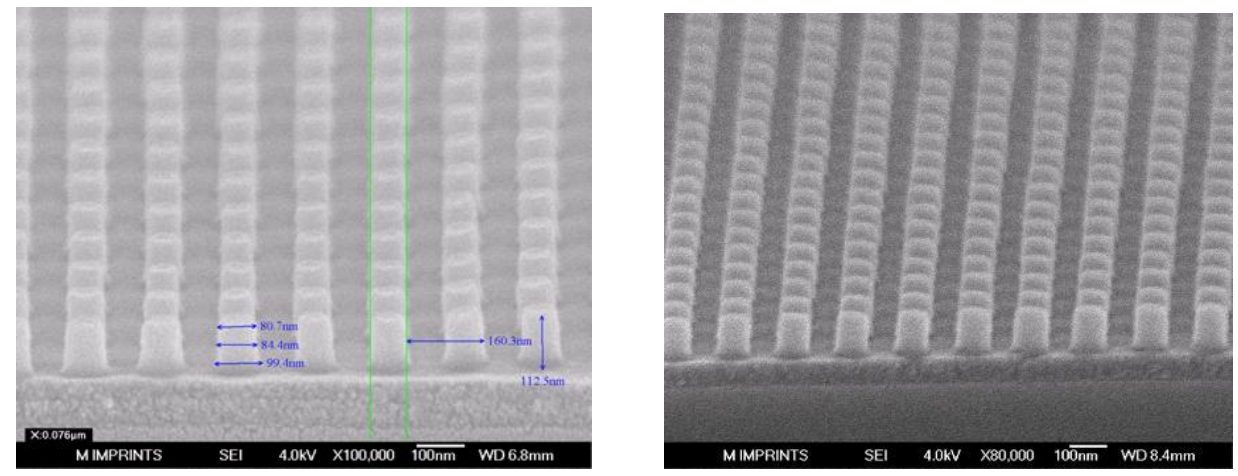

Figure 5: Template replication results. Left hand micrograph shows imprinted features from the ebeam master template, the right hand micrograph shows imprinted features from the replicated template
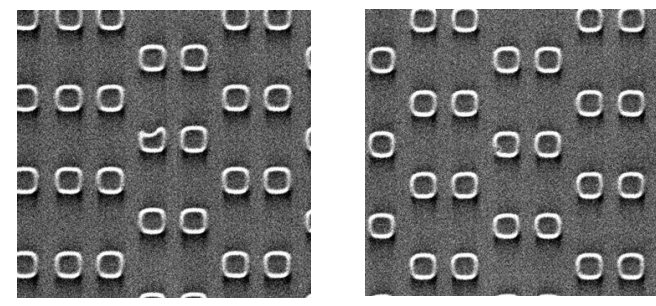

Figure 6a
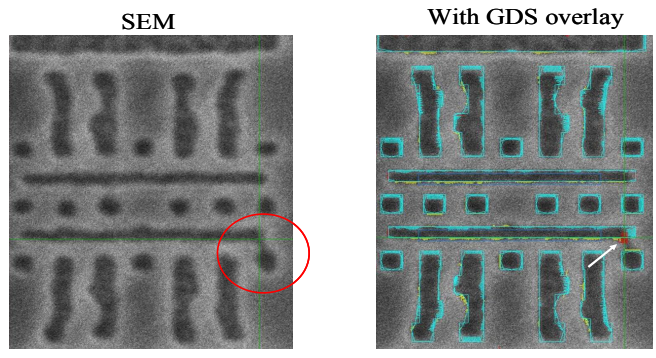

Figure $6 \mathrm{~b}$

Figure 6: Template defect inspection results.

Fig 6a showing ES-32 inspection down to sub 30nm resolution (from ref 12) and Fig $6 \mathrm{~b}$ showing die to data base results at $20 \mathrm{~nm}$ (from ref 13)

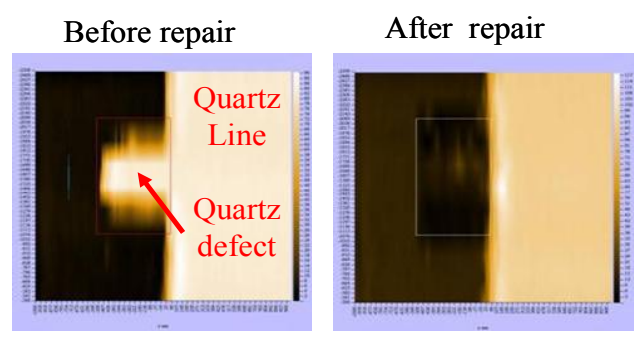

Figure 7a

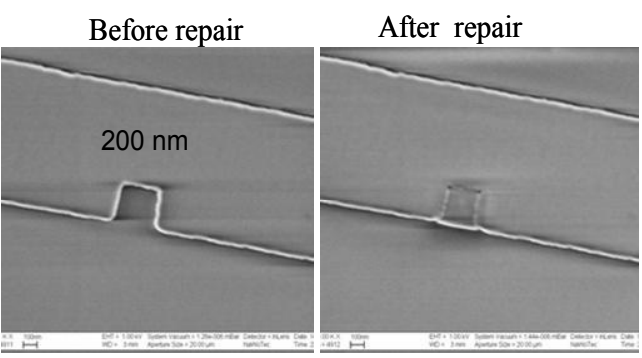

Figure $7 \mathrm{~b}$

Figure 7: Template defect repair results Fig 7a showing mechanical removal of defect (from ref 14) and Fig $7 \mathrm{~b}$ showing repair of a missing defect using ebeam enhanced deposition (from ref 15) 


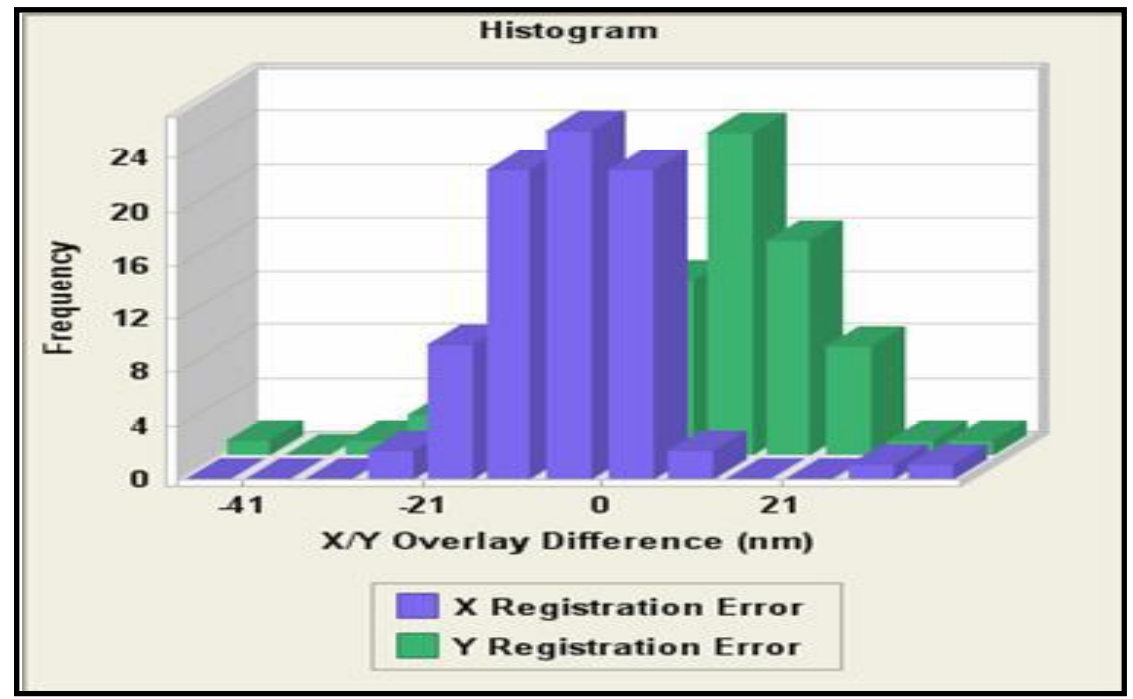

Figure 8: Overlay data from imprint patterns over $193 \mathrm{~nm}$ optically exposed underlayers. 32 fields per wafer and 81 locations per field (from ref 20)

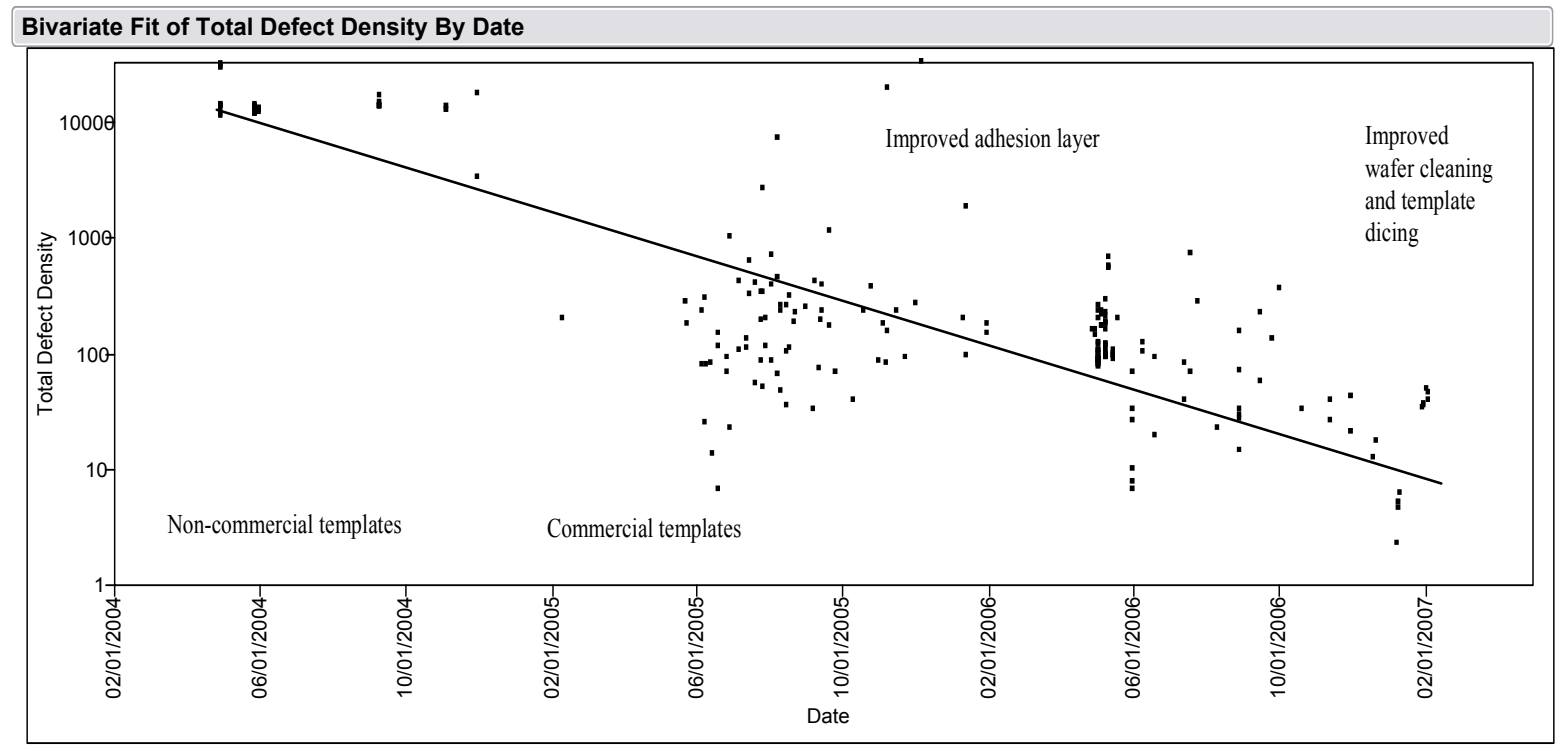

Figure 9: Defect improvement over time for SFIL.(from ref 21) 

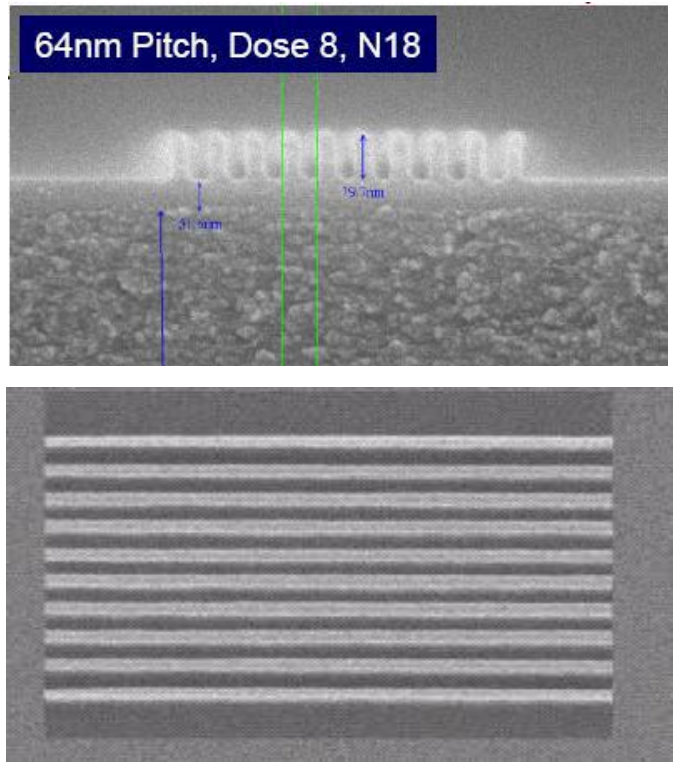

Figure 10: Cross section and top view images of $32 \mathrm{~nm}$ half pitch imprinted features showing excellent wall angle and line edge roughness (from ref 25, with a template made by DNP)
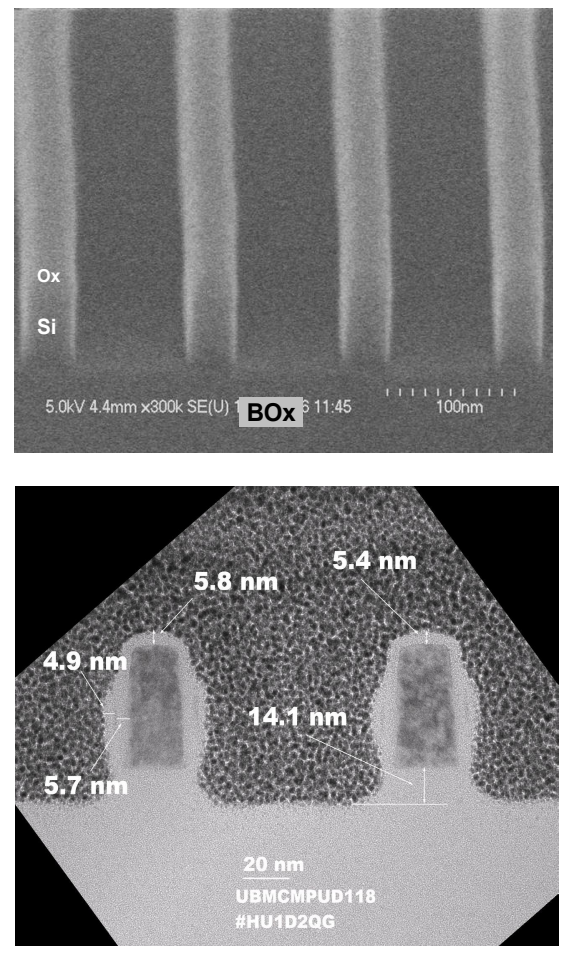

Figure 12: Cross section views of experimental device from IBM (ref 32). Top micrograph, $27 \mathrm{~nm}$ silicon fins, imprinted and etched; lower micrograph, cross section of the device
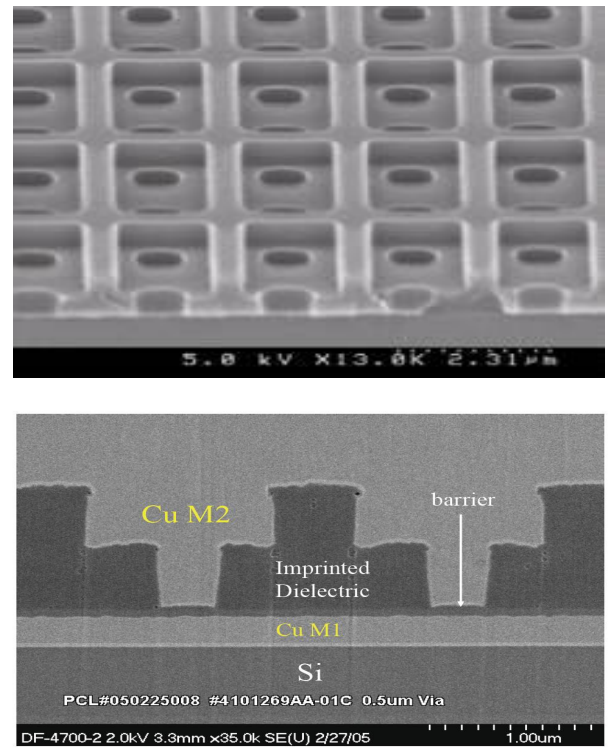

Figure 11: Imprinted low-k dual damascene results showing the top view of the imprinted low-k dielectric and a cross section after barrier metal and copper fill (from ref 29)

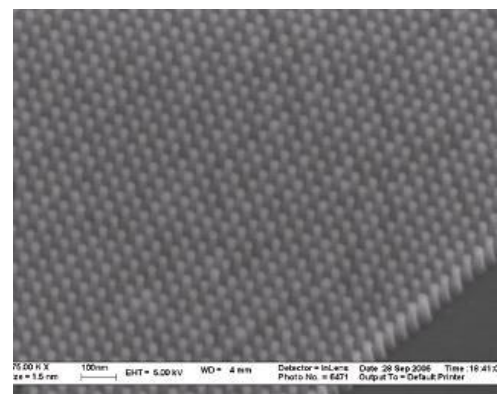

Figure 13: Sub 30nm half pitch patterns for BPM (from ref 34)

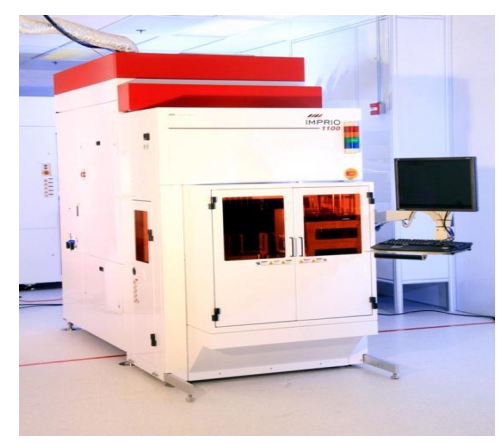

Figure 14: Imprio-1100Whole wafer, conformal imprinter for LED, optical component and BPM applications 


\title{
The Effect of Photoresist/Topcoat Properties on Defect Formation in Immersion Lithography
}

\author{
G. M.Wallraff, C. E. Larson, G. Breyta, L. Sundberg, D. Miller \\ IBM Almaden Research Center, 650 Harry Road, San Jose, CA 95120 \\ D. Gil, K. Petrillo \\ IBM Albany Nanotech, 255 Fuller Road, Albany, NY 12203 \\ W. Pierson \\ ASML Netherlands B.V.
}

\begin{abstract}
The interaction of water with the photoresist film stack is proving to be a key factor in the current generation of 193-nm immersion lithography. Photoresist performance, CD control, optics lifetime, defectivity, overlay and possibly even tool throughput can all be affected by this interaction. Defect control has been an area of increasing concern as the source of the defects can be quite different than that found in conventional dry lithography [1]. Defects can originate from the UPW (Ultra Pure Water) either as particulates or as dissolved solids that precipitate from residual droplets left behind after scanning. Another source of defects can be particulates generated by the immersion fluid as it flows through the exposure tool or as a consequence of water contact with the resist film or resist/topcoat film stack. Recently there have been reports of printable defects due to stains or "watermarks" on the surface of the photoresist [2].

In this report we describe techniques for the visualization of watermarking and particulate formation on a variety of film surfaces. We also describe experiments testing the staining of a variety of water contaminants and additives and their effect on imaging performance. We will also describe the effect of different topcoats on imaging and defectivity in terms of their surface properties.
\end{abstract}

Keywords: immersion lithography, chemically amplified resist, water spots, defects gmwall@almaden.ibm.com (408 927-2503)

\subsection{INTRODUCTION}

Several years ago 193 immersion lithography development issues such as water purity, index changes due to fluid heating, fluid handling, lens contamination, and resist performance degradation were all regarded as potential high risk areas [3]. While many of these concerns have been addressed the topic of resist performance, particularly as it regards defect formation, remains an issue. Early immersion experiments on 1st generation low NA exposure systems often showed extremely high defect counts [1]. Further testing showed that most of these defects were due to particulates entrained in the immersion fluid, subsequent tool design modifications have largely eliminated defects of this type. There are however other sources of defectivity that are harder to eliminate. A primary source of concern are water droplets left on the wafer after passage of the immersion lens. (Figure 1)

Advances in Resist Technology and Processing XXIII, edited by Qinghuang Lin

From Proc. of SPIE Vol. 6153, 61531M, (2006) · 0277-786X/06/\$15 · doi: 10.1117/12.657179

xxxvii 


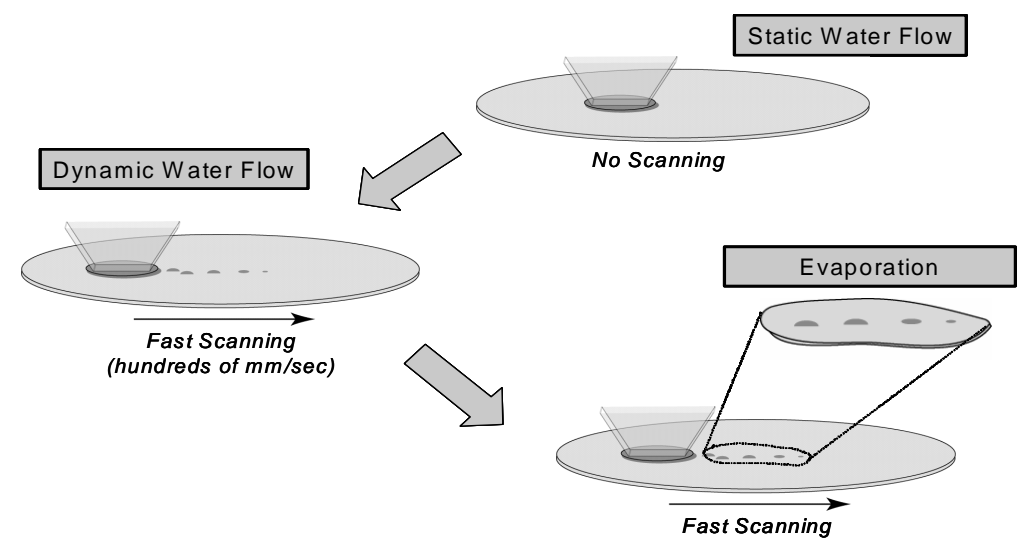

Figure 1. Schematic showing origins of residual droplets during fast scanning in immersion lithography

These droplets can be the source of particles from dissolved solids such as soluble silica or extracted photoacid generator. For example only $0.05 \mu \mathrm{l}$ residual water (with a concentration of dissolved solids of $2 \mathrm{ppb}$ ) could yield as many as 100 particles of 0.1 micron diameter assuming a nominal density of $2 \mathrm{~g} / \mathrm{cm}^{3}$. Depending on the design and the route of the immersion lens during exposure the these dried deposits can serve as imaging defects following evaporation. Another type of droplet based defect has been described in terms of a watermark or stain is believed to be due to compositional changes in or on the surface of the resist film. Examples of different types of particulate and stain defects are shown in Figure 2.
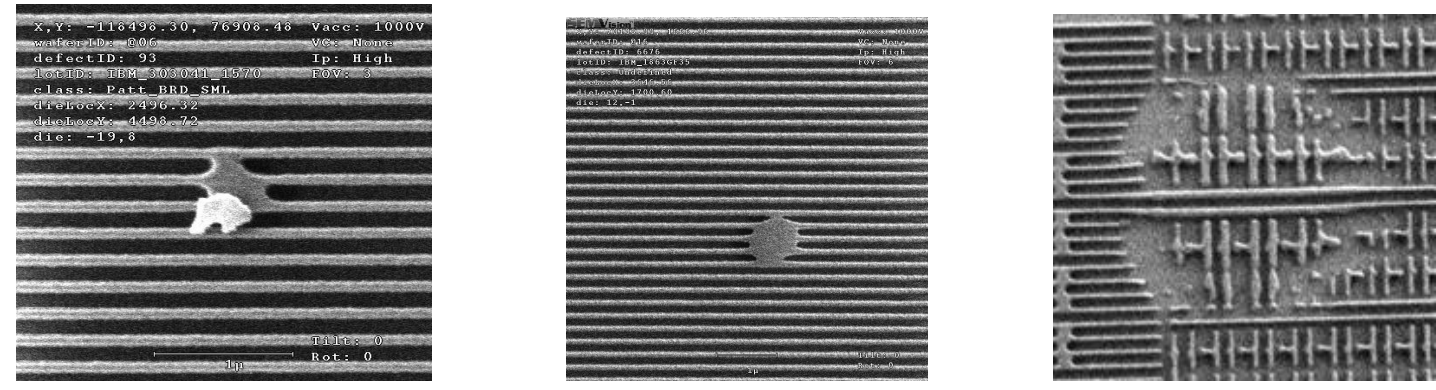

Figure 2. Representative defects found in immersion lithography

Early in the study of 193 immersion lithography it was demonstrated that significant water absorption by the resist (and or topcoat) and significant PAG extraction was observed for standard resists under immersion conditions (Figure 3) [4]. The most common perfluorosulfonate sulfonium salts display rapid extraction rates (on the order of several seconds, fast enough to be a concern even in the high scan rates employed in production tools) [5]. The rate of extraction was found to be structure dependent with more surface active PAGs being extracted fastest [6]. Because of this topcoats have been introduced where the extent of PAG extraction is much less. Two types of topcoat have been developed, one that is stripped with an organic solvent prior to development and the other type that is removed during normal development with aqueous base. In 
general the solvent stripped topcoats seem to be more effective at minimizing PAG leaching and have more hydrophobic surface properties (higher contact angles) that than the other materials. However even with a topcoat present resist defects and stains are a significant problem. In the following report we will describe experiments designed to better understand the pathways for defect generation.

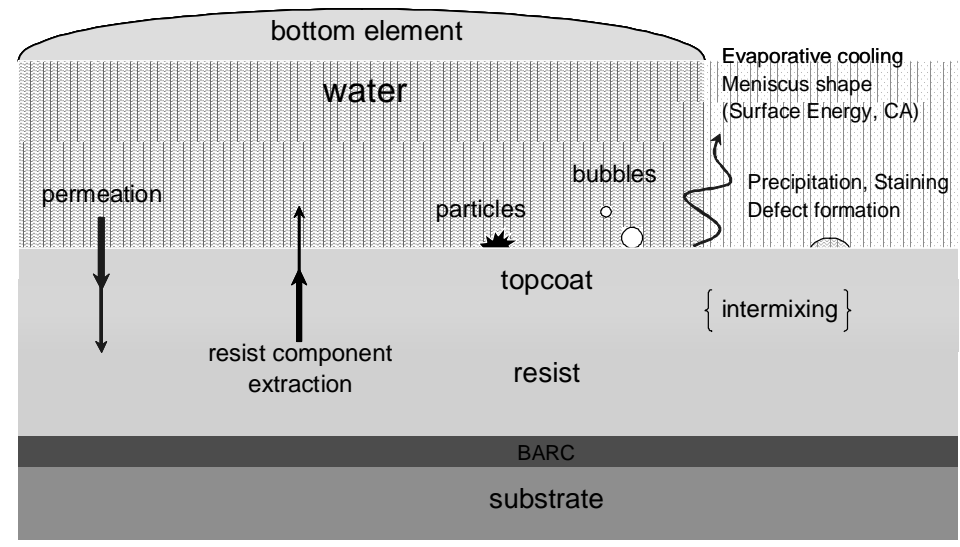

Figure 3. Summary of different water/resist/topcoat interactions in immersion lithography

\subsection{EXPERIMENTAL}

\subsection{Materials}

Different grades of water were employed depending on the particular experiment. Unless otherwise indicated water was stored in Fluoroware bottles and dispensed employing Eppendorf pipettes.

- $\quad$ HPLC grade water (Glass Bottle)

- $\quad$ Laboratory DI Water, 18.2 M Ohm (Total Organic Content measured at 2 - 4 ppb) MilliQ Synthesis System

- $\quad$ Inlet water from an ASML 1150i Immersion tool (Balaz analysis)

The TPS-BFBS and perfluorobutane sulfonic acid employed as resist additives were obtained from commercial sources and used at concentrations of 2.5 and $60 \mathrm{ppm}$ respectively. The Rhodamine 6G Perfluorobutane salt (RH6G PFBS) employed as a fluorescent PAG analogue at a concentration of $0.9 \mathrm{ppb}$ This material was synthesized from hot saturated solution of Rhodamine 6G in water which was added dropwise to a stirring solution of potassium perfluorobutanesulfonate $(9.1 \%$ in water). The resulting mixture was filtered and washed with cold water, then dried further in a $65 \mathrm{C}$ vacuum oven. The structure of the Rhodamine cation (and the corresponding sulfonium cation) is shown in Figure 2 along with the absorption spectra of Rh6G PFBS and the parent Rhodamine dye (as the chloride salt). The fluorescent polystyrene particles were obtained from Molecular Probes Corporation. Depending on the experiment the sizes ranged from $20 \mathrm{~nm}$ to 1.8 microns in diameter. Commercial $193 \mathrm{~nm}$ resists and topcoats were employed. 

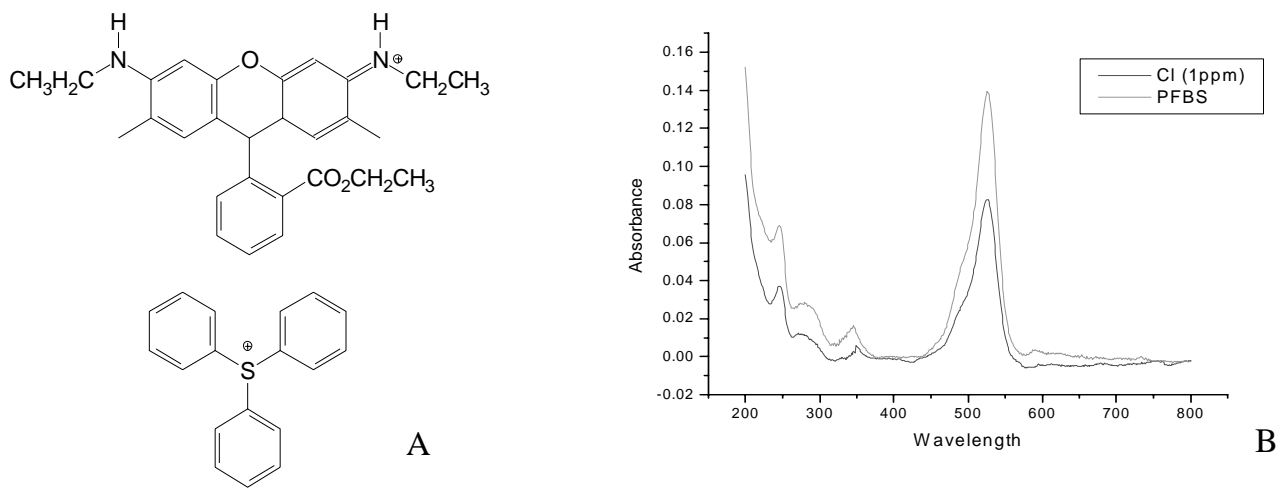

Figure 4. A) Structural comparison of rhodamine dye (top) and triphenyl sulfonium cations (bottom). B) Absorbance spectrum of rhodamine chloride and rhodamine perfluorobutane sulfonate.

\subsection{Characterization and Analysis}

Exposures were done on an $193 \mathrm{~nm}$ ISI microstepper. $125 \mathrm{~mm}$ wafers ( 1 micron of $\mathrm{SiO}_{2}$ on silicon with etched alignment frames) were coated with a BARC/Resist/Topcoat film stack of either AR24/JSR 1682J or AR24/JSR 1682J/TCX014. The wafers were exposed using a test mask consisting of 4 different line space arrays of differing pitch (110 and $130 \mathrm{~nm}$ lines). The exposed field on the wafer consisted of 5 rows of 25 identical exposures. Following exposure the wafer was kept in the stepper and $0.5 \mu \mathrm{l}$ droplets were applied to multiple exposed fields within a given row. Each row was treated with a different additive solution. After the droplets had dried (approximately 10 minutes) the wafers were post apply baked and developed in the usual fashion.

Contact angles were measured on a Dataphysics OCA 20 instrument. Analysis of PAG leaching was performed as previously described [4]. The 1682J resist had a saturation level leaching value of $29.3 \mathrm{ppb}$ for PAG, the same resist with topcoat had a value of $0.96 \mathrm{ppb}$. Droplet evaporation was measured using either a Leica INM100 microscope with an attached Sony video camera or a Olympus BX51 fluorescent microscope/PictureFrame image capture system. ESCA analysis was performed on a Physical Electronics Quantum 2000 ESCA Microprobe with a monochromatic $\mathrm{Al} \mathrm{K}$ a source.

\subsection{Results and Discussion}

\subsection{Evaporative Processes Leading to Defect Formation}

To better understand how residual droplets might generate defects in immersion lithography we observed droplet evaporation on a variety of different surfaces for different types of water. The experiments were performed using an optical microscope and a standard video camera. Figure 5A shows an individual video frame taken during the evaporation of a $0.3 \mu \mathrm{l}$ droplet of HPLC grade water on a clean silicon surface (freshly washed and ashed). Note the interference fringes (Figure 5a) of this fast evaporating "flat" droplet (static contact angle $<10$ degrees). Figure $5 \mathrm{~b}$ is a later frame after the droplet has evaporated with no obvious residue. This is observed even when the water is known to be contained through its contact with a glass storage bottle. In this experiment 
no visible waterborne or airborne particles or residue is observed at the highest magnification available $(150 \mathrm{X})$.

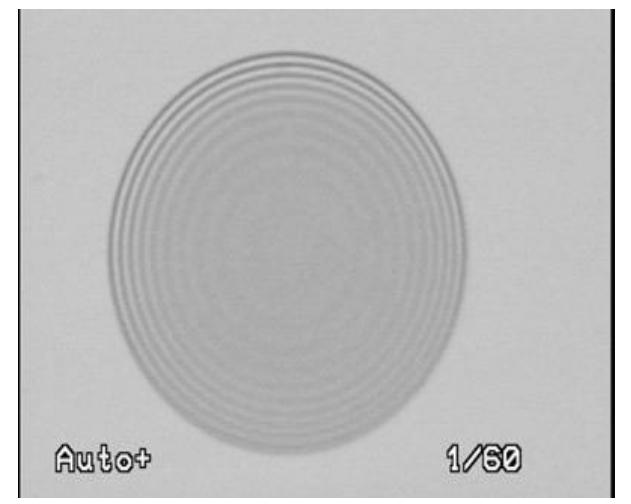

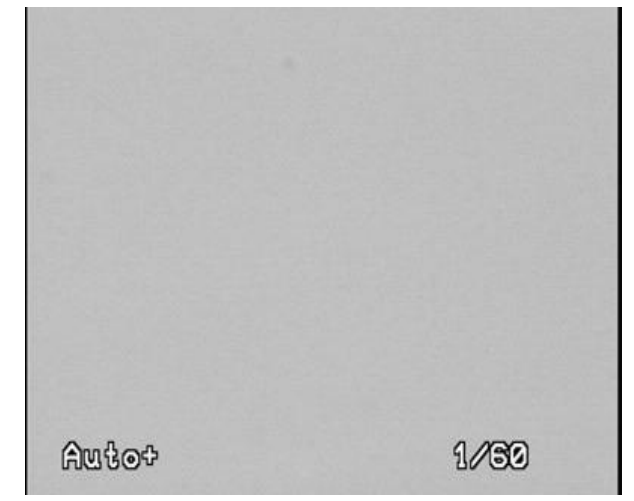

Figure 5. (A) Partially evaporated water droplet on clean silicon (B) Same view after evaporation

Figure 6 shows a similar timed evaporation study but in this example the water droplet was placed on a resist stack consisting of an aqueous developable topcoat and a commercially available 193 resist (JSR 237J). The measured diameter of the initial droplet is approximately 1.5 $\mathrm{mm}$, the residual stain is approximately 100 microns in diameter. The formation of this type of stain was observed on all of the eight 193 resists and five topcoats that we have studied Figure 7. In fact residues were also observed on BARCs as well as HMDS primed wafers.
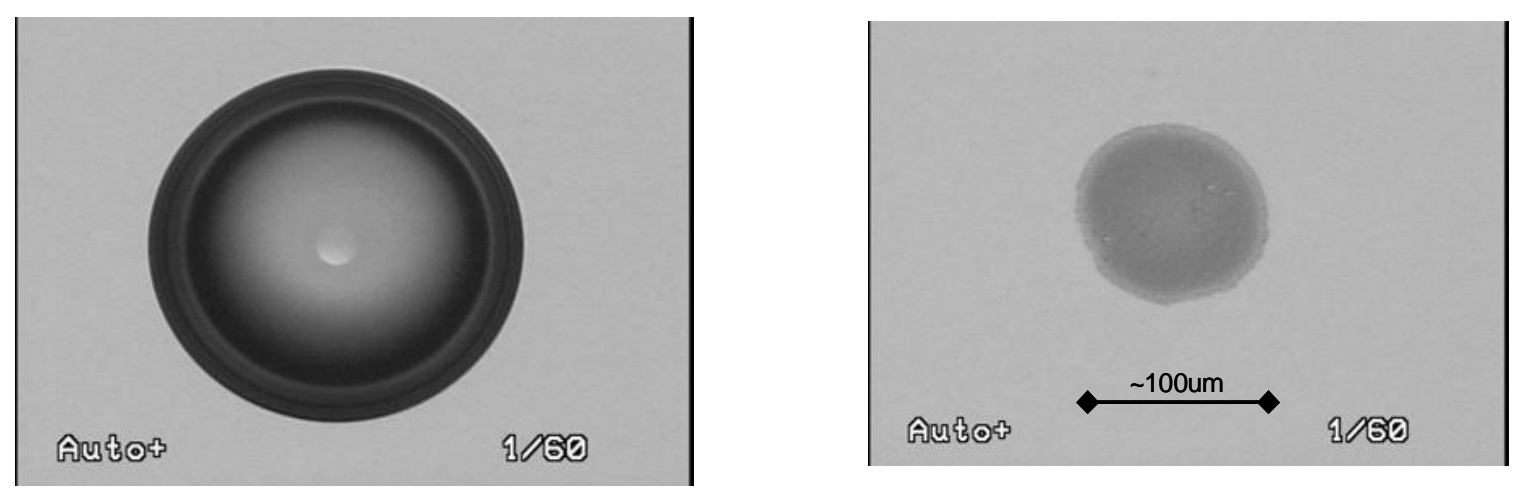

Figure 6. (A) Water droplet on JSR 1682 resist/TCX007 topcoat (B) Same view after evaporation

Dissolved impurities, particulates in the water, airborne particulates that are present either on the wafer or fall on the water droplet during the course of the experiment all are present and will contribute to residue on all types of surface. The absence of visible stain in the case of the silicon surfaces is believed to be due to the way that water evaporates on a low static contact angle surfaces where the residue is spread over a relatively large area. In fact when a water droplet is placed on other inorganic surfaces that have higher contact angles $(\mathrm{Cu}, \mathrm{Au}$, "old" $\mathrm{Si})$ a residue is observed. 

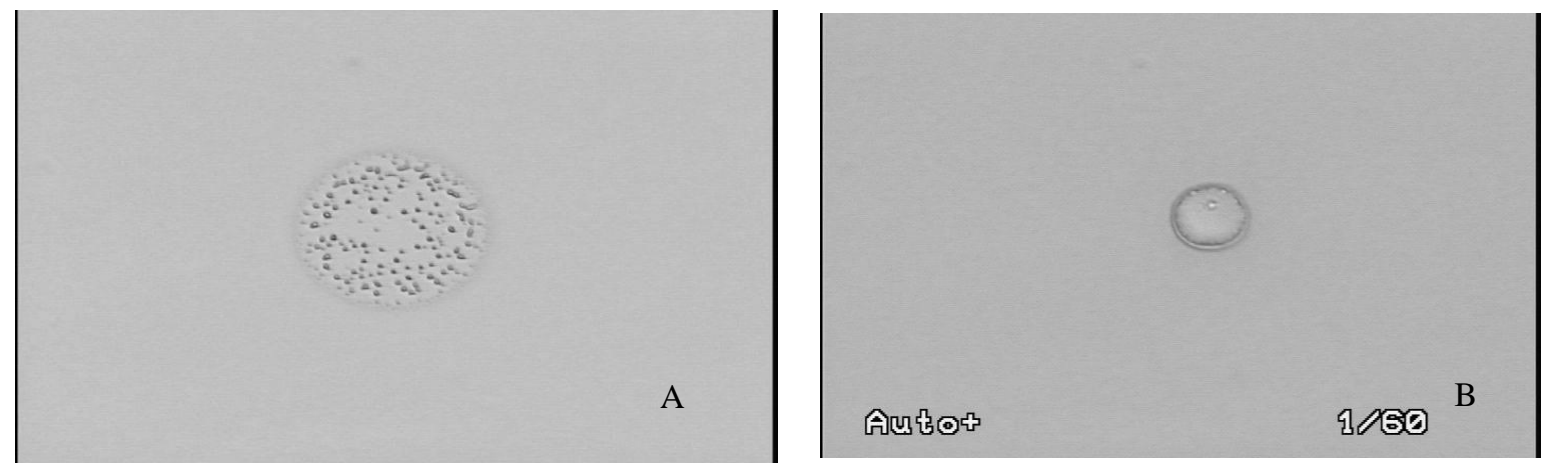

Figure 7. (A) Residue on JSR 1682 J photoresist (B) and solvent developable TOK TSP3A topcoat on silicon

To better understand the role that contact angle plays in residue formation we took videos of the evaporation of water droplets containing fluorescent latex particles ( 0.5 micron diameter $)$ on bare silicon and resist coated wafers. This is a variant of the classic "coffee ring" experiment described by Deggan [7]. Figure 8A and 8B shows individual video frames taken during evaporation on a silicon and resist coated surface (JSR 1682J). In the case of the low contact angle Si surface the polystyrene beads readily escape the receding contact line and are distributed over a relatively large area on the wafer as seen in the white light photomicrograph 8A. On the high contact angle resist surface the latex particles remain contained within the evaporating drop. This can be seen in the row of fluorescent beads in Figure $8 \mathrm{~B}$ at the edge of the partially evaporated droplet. Due to the lensing effect of the droplet a fluorescent image was required to view the motion of the particles. The relationship between the final dried stain and the position of the dried particles on a resist surface can be seen in the optical and fluorescent photomicrographs in Figure $8 \mathrm{C}$ and $8 \mathrm{D}$.

Based on the above experiments it seems clear that resist or topcoat surfaces with high contact angles tend to concentrate defects and particulate impurities whatever their origin. The next question is how much of the stain is due to adventitious impurities and how much is due to extracted materials. ESCA analysis of the stains showed only increased levels of inorganic contaminants (Na, Ca, Si, B) that are likely due to dissolved impurities (HPLC grade water from a glass bottle was used in this experiment). There was no definitive evidence for increased concentrations of PAG or other resist components. Attempts at removing all possible extractable components by presoaking the resist or topcoat coated wafers prior to spotting were unsuccessful at eliminating stains. As both dissolved materials and extracted materials can give rise to stains and it is impossible to completely eliminate water impurities we deliberately added impurities to the water used in the spotting experiments to see what effect they would have on defect formation. These experiments are described below. 

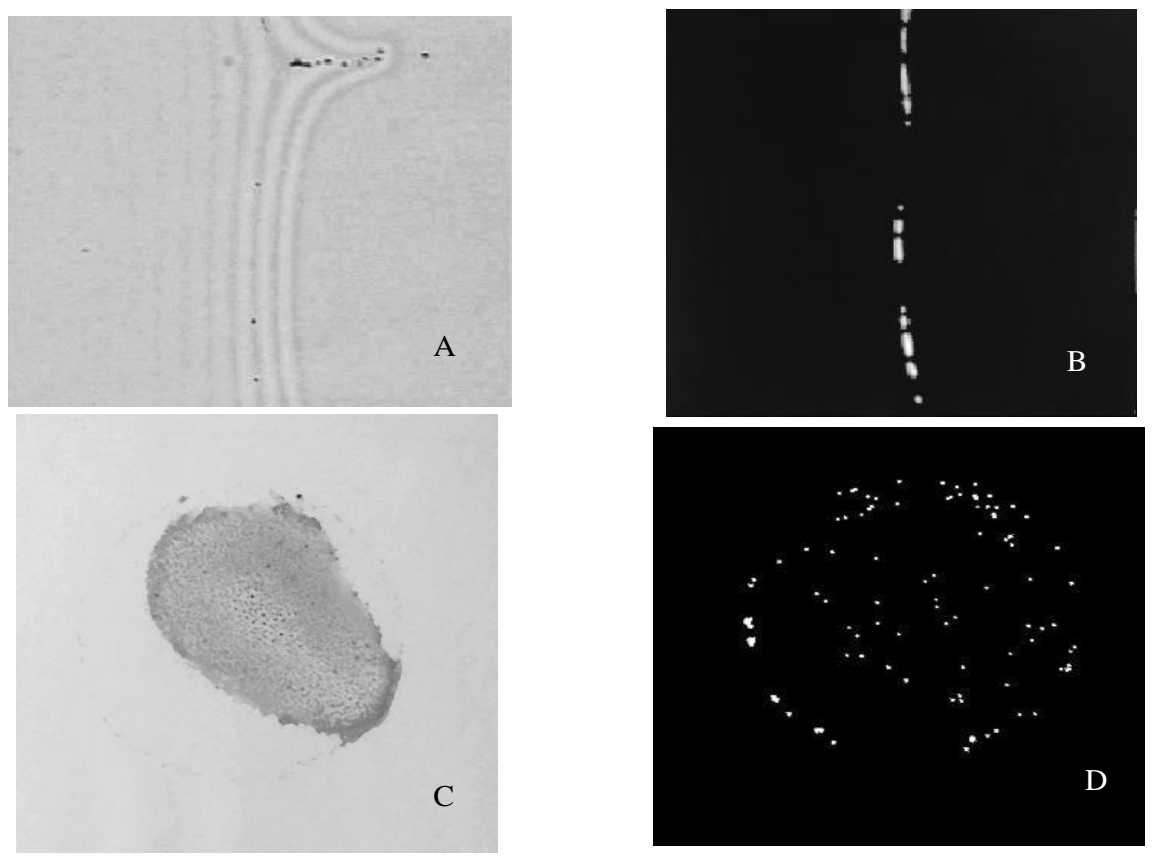

Figure 8. (A) Video frames of the edge of an evaporating water droplet containing $500 \mathrm{~nm}$ fluorescent latex particles on (A) a silicon surface (white light image) and (B) a resist surface (fluorescent image). (C) White light image of dried stain on resist surface. (D) Fluorescent image of same stain showing location of fluorescent particles

\subsection{Effect of Added Impurities on Imaging Performance}

As described in the experimental section exposed wafers (JSR 1682 resist and 1682/ TCX014) were spotted with solutions of several different additives after exposure and before PEB and development, when the imaging process believed to be most sensitive to contamination. The results of spotting experiments with resist additives are summarized below.

- DI Water

- Defects are readily for samples with and without topcoat (Figure 9A,B)

- Defects are much smaller than original droplet $(\sim 1.5 \mathrm{~mm}$ diameter $)$ and are approximately the same size as residue observed in evaporation experiments

- $\quad$ Photoacid Solution (60 ppm)

- Loss of pattern over large area - image flare observed in both systems (9C)

- Topcoat showed circular ridged pattern (9D)

- PAG Solution (TPS-PFBS 2.5 ppm)

- Mottled residue seen in both cases (9E)

- Fewer defects with topcoat (9F)

- Solution of Fluorescent PAG Analogue (Rh6G-PFBS 0.9 ppm)

- Obvious staining of underlying resist - observed even with topcoat $(10 \mathrm{~A}, \mathrm{~B})$

- Observed defects much smaller than original stain pattern (10C)

- Fewer defects in presence of topcoat 
The pure water stains were the most alike on both surfaces but stains or defects were observed with all added impurities. Added photoacid (at a high concentration of $60 \mathrm{ppm}$ ) has the expected result of destroying the pattern over a large area of the exposed die for both resist only (Figure 9A) and resist/topcoat (Figure 9B) although in the later case a pronounced ring stain is observed. Added PAG (Figures 9C and D) leaves residue stains larger than those observed with water droplets alone (Figure 9E and F). The most interesting results were observed with the fluorescent rhodamine PAG analogue. Figure 10b shows a photomicrograph of a a fluorescent stain of the same size as the initial drop $(\sim 1.5 \mathrm{~mm}$ diameter $)$ in the developed resist pattern. A clear fluorescent stain, albeit blurry, is observed for the resist topcoat combination as well, indicating that the fluorescent perfluorobutane salt had effectively penetrated both topcoat and the resist film. As with all of the spotted defects the stain or watermark is on the order of $50-100$ microns in diameter.

Stain penetration through the topcoat was not observed with the TSP3A solvent developed topcoat. Figures 10-D,E,F display a view of the original droplet, a higher magnification view of the residual stain and a fluorescent image of the same stain on a patterned wafer. Note that the fluorescent material is confined to the residue region only, there is no evidence that the topcoat, or the underlying resist, was stained by the dye as in the previous example.
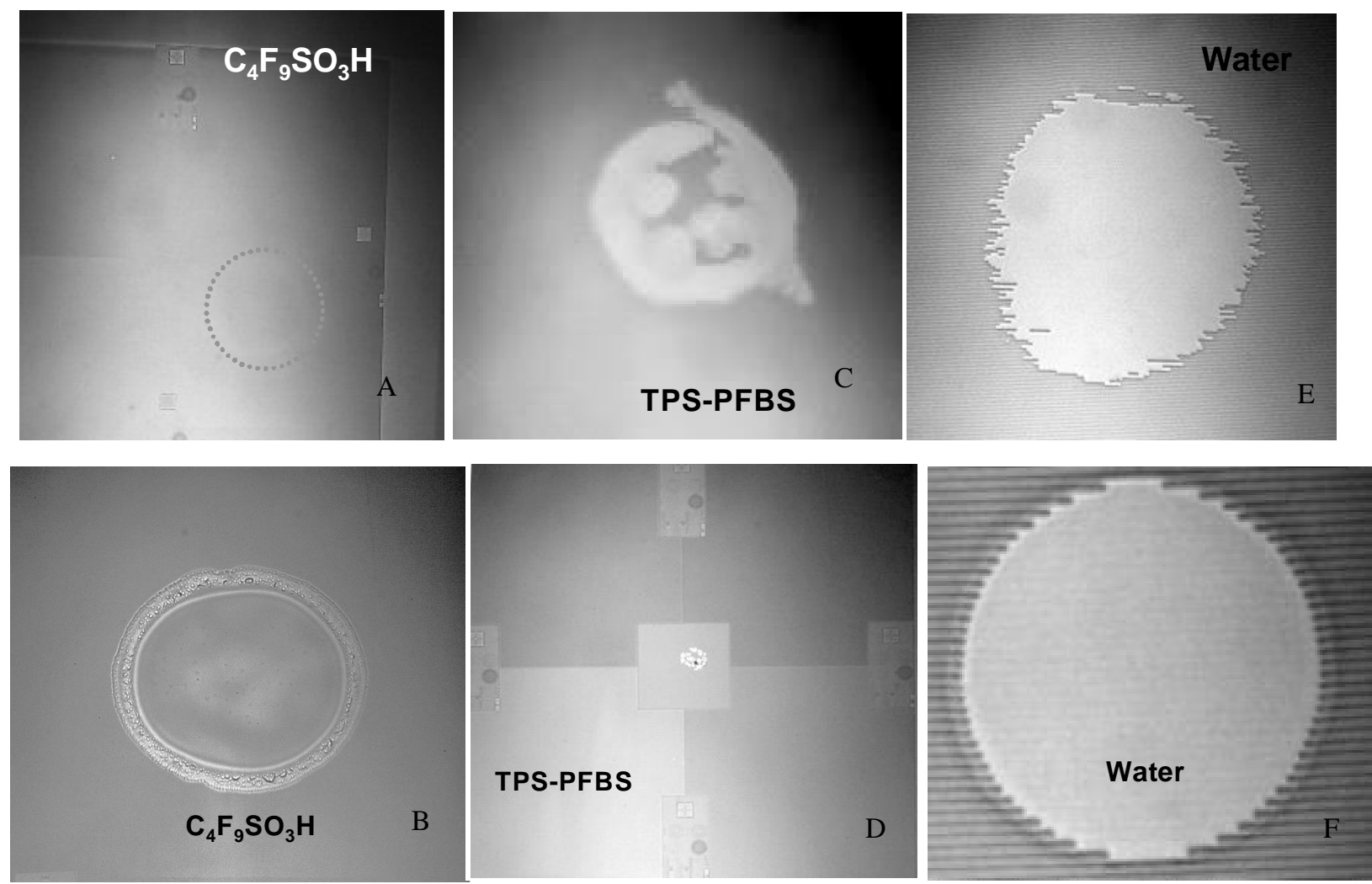

Figure 9. Impurity spotting on patterned wafers spotting on 1682J resist only (A,C,E), spotting on 1682J/TCX014 (B,D,F). 


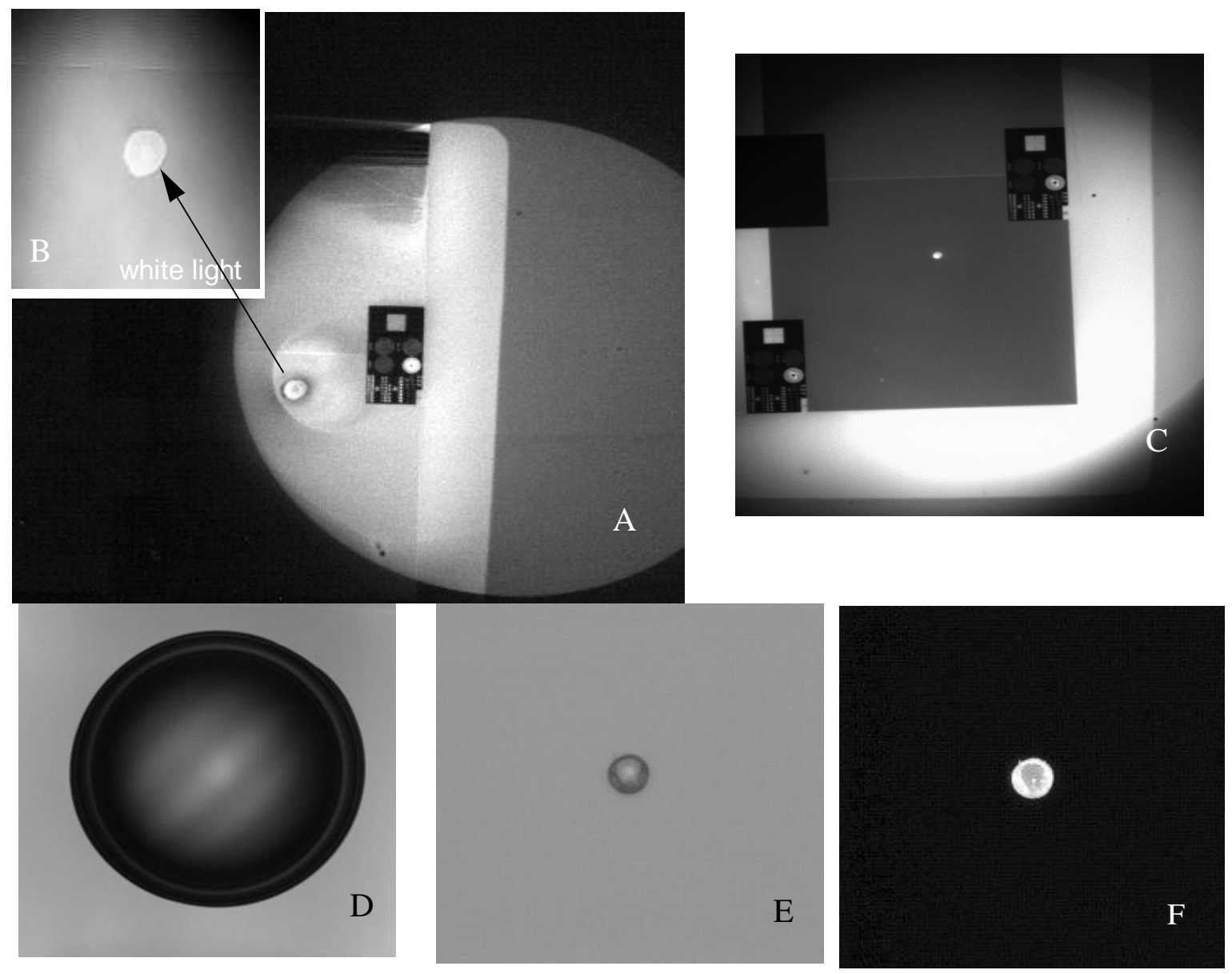

Figure 10.Spotting experiments with fluorescent PAG analogue. (A) Fluorescent image of $0.5 \mu 1$ droplet on patterned resist. (B) White light image of residual stain. (C) Fluorescent image of 1682J/TCX014 after development and removal of the topcoat. Droplet evaporation on TOK TSP3A topcoat. (D) Low magnification of original droplet (E) white light image after evaporation (F) same magnification fluorescent image of residue shown in (E).

\subsection{SUMMARY}

The evaporation of residual water droplets during the immersion lithography process is believed to lead to a variety of defects including particles, stains or watermarks. Optical microscopy of large $(0.5 \mu \mathrm{l})$ droplets show stain formation on all organic polymer surfaces tested. Droplets on clean silicon surfaces (native oxide) show no visible evidence of residue even when water contaminated with dissolved silica is used. Video analysis of droplets containing fluorescent particles show the particles widely dispersed on surfaces with low contact angles such as silicon and concentrated in small 50 - 100 micron diameter regions on resist or topcoat surfaces. ESCA analysis of residues showed only expected inorganic impurities, no clear evidence of changes in the composition of the resist film were observed. 
Water droplets containing either added PAG, photoacid or a fluorescent PAG analogue spotted on patterned wafers after (dry) exposure but before PEB and development all left residues. Defects are observed on resist only as well as on resist/topcoat. In the case of pure water spotting the defects appear nearly identical in both cases. The use of a fluorescent dye shows obvious staining of both resist and resist/TC film stacks over an area spanning the contact area of the original droplet. The area of the concentrated residue is much smaller. Similar staining is not observed with the solvent developed topcoat tested.

\subsection{ACKNOWLEDGEMENTS}

We would like to acknowledge the JSR Micro Corporation in Sunnyvale, CA for supplying the formulated resists and topcoats used in this study. We would also like to thank John Barnes and Jim Warren of ASML. Carol Boye, Jessica Provost, Butch Halliday, Joe Conners of IBM E\&TS at Albany Nanotech and Blake Davis of IBM Almaden.

\subsection{REFERENCES}

1. Darío Gil, Timothy A. Brunner, Carlos Fonseca, Nakgeuon Seong, Bob Streefkerk, Christian Wagner and Marco Stavenga, J.Vac.Sci.Techn.B, 22(6), Nov. 2004

2. $\quad$ D. Kawamura et al, Proc SPIE 5753818 (2005).

3. $\quad 2^{\text {nd }}$ Immersion Lithography Workshop, San Jose CA, July 2003

4. G. M. Wallraff, C. E. Larson, B. Davis, D. Miller, L. Sundberg, W. Conley Proc.of the 13th Intl. Conf. on Photopolymers, Soc. of Plastics Eng. 33 (2003), W. Hinsberg, G. Wallraff, C. Larson, B. Davis, V. Deline, S. Raoux, D. Miller, F. Houle, J. Hoffnagle, M. Sanchez, C. Rettner, L. Sundberg, D. Medeiros, R. Dammel, W. Conley, Proc. SPIE, 5376, 21, (2004)

5. R. Dammel, G. Pawlowski, A. Romano, F. M. Houlihan W. Kim, R. Sakamuri, D. Abdallah, Proc. SPIE, 5376, 21, (2004)

6. R. D. Allen, P. J. Brock, L. Sundberg, C. Larson, G. M. Wallraff, W. Hinsberg, J. Meute, T. Shimokawa, T. Chiba, M. Slezak, J. Photopolymer Sci. and Tech. 18615 (2005), 18(5), 6

7. Robert D. Deegan, Olgica Bakajin, Todd F. Dupont, Greb Huber, Sidney R. Nagel, Thomas A.Witten Nature 389, 827 (1997) 